Review

\title{
Functional Nanofibrous Biomaterials of Tailored Structures for Drug Delivery-A Critical Review
}

\author{
Zhen $\mathrm{Li}^{1,2,3}{ }^{10}$, Shunqi Mei ${ }^{2,3, *}$, Yajie Dong ${ }^{1,2,3}$, Fenghua She ${ }^{1}$, Yongzhen $\mathrm{Li}^{4}{ }^{4}$, Puwang $\mathrm{Li}^{4}$ and \\ Lingxue Kong $1, *(\mathbb{B})$ \\ 1 Institute for Frontier Materials, Deakin University, Geelong, Victoria 3216, Australia; \\ zkj@deakin.edu.au (Z.L.); dongy@deakin.edu.au (Y.D.); mary.she@deakin.edu.au (F.S.) \\ 2 School of Mechanical Engineering and Automation, Wuhan Textile University, Wuhan 430073, China \\ 3 Hubei Key Laboratory of Digital Textile Equipment, Wuhan Textile University, Wuhan 430073, China \\ 4 Key laboratory of Tropical Crop Products Processing, Ministry of Agriculture and Rural Affairs, \\ Agriculture Products Processing Research Institute, CATAS, Zhanjiang 524001, China; \\ liyongzhen@catas.cn (Y.L.); puwangli@yahoo.com (P.L.) \\ * Correspondence: sqmei@wtu.edu.cn (S.M.); lingxue.kong@deakin.edu.au (L.K.)
}

Received: 29 April 2020; Accepted: 1 June 2020; Published: 8 June 2020

\begin{abstract}
Nanofibrous biomaterials have huge potential for drug delivery, due to their structural features and functions that are similar to the native extracellular matrix (ECM). A wide range of natural and polymeric materials can be employed to produce nanofibrous biomaterials. This review introduces the major natural and synthetic biomaterials for production of nanofibers that are biocompatible and biodegradable. Different technologies and their corresponding advantages and disadvantages for manufacturing nanofibrous biomaterials for drug delivery were also reported. The morphologies and structures of nanofibers can be tailor-designed and processed by carefully selecting suitable biomaterials and fabrication methods, while the functionality of nanofibrous biomaterials can be improved by modifying the surface. The loading and releasing of drug molecules, which play a significant role in the effectiveness of drug delivery, are also surveyed. This review provides insight into the fabrication of functional polymeric nanofibers for drug delivery.
\end{abstract}

Keywords: nanofibrous biomaterials; nature fiber biomaterials; biopolymers; drug delivery; nanofiber technology

\section{Introduction}

Nanofibers are a significant kind of biomaterial that could be used for biomedical applications, due to their special structure and properties such as high surface area [1], superior mechanical properties [2], high porosity [3], and low density [4]. Drug delivery is one of the most important emerging applications of nanofibers $[5,6]$, because nanofibers have similar structural features and functions to those of extracellular matrix (ECM). The ideal drug delivery system can deliver and release a well-controlled amount of drug for a suitable period of time into a target site of the human body [7].

Nanofibrous biomaterials can be prepared from a wide range of polymers for drug delivery [8]. Polymeric biomaterials can be divided into natural and synthetic polymeric biomaterials. Natural polymeric biomaterials include chitosan, chitin, cellulose, gelatin, collagen, pectin, proteins, gelatin, and lignin [9]. These natural polymers are biocompatible and can be used to mimic ECM [10]. However, they are very difficult to form into continuous nanofibers [5]. Therefore, synthetic polymeric biomaterials with biodegradable properties have been composited with those natural polymeric biomaterials, due to their molecular weights being long enough to fabricate continuous nanofibers after elongation. Polymers that have been approved as biomaterials such as polyethylene oxide (PEO), 
polycaprolactone (PCL), poly(lactic-co-glycolic) acid (PLGA) and Poly(N-vinylpyrrolidone) (PVP) are usually utilized to form composites with natural polymers for nanofiber fabrication and for sustainable and controlled drug release [11].

Due to the superior properties of nanofibers, various nanofiber production technologies have been studied and utilized by many studies, including electrospinning, centrifugal spinning, solution blowing, phase separation, and self-assembly. Recently, electrospinning has been one of the major methods for nanofiber production, because of its numerous advantages, such as simple principles and equipment, broad material choice, and fabrication of nanofibers with versatile and uniform morphologies [12-14]. Other technologies for nanofiber production have also been reported and studied by many researchers [15]. The advantages and disadvantages of those technologies for fabrication of functional nanofiber scaffolds for drug delivery are reported.

Morphology and structure of nanofibrous biomaterials also significantly influence the function and effectiveness of drug delivery [16]. The morphology and structure involve fiber diameter, fiber cross-section shape, directionality, porosity and dimensionality of scaffold. For example, natural ECMs are usually highly 3D porous collagen nanofibers with diameters in the range of 50-500 nm [11]. In addition, many tissues (like tendon, muscle tissues, ligament and tympanic), cells and ECMs are highly aligned. Therefore, the fabricated nanofiber scaffolds should have similar morphology and structure to mimic the native ECM during delivery of drugs and regenerate damaged tissue.

The drug loading methods and drug release rate significantly influence the effect of drug delivery. Drug loading methods can be divided into chemical and physical adsorptions. Drug release rate from nanofibers is determined by various factors, including drug diffusion, fiber erosion and biodegradation. This review introduces the current state of development in the field of drug loading molecules on nanofibers for drug delivery. It will be followed by discussion and comparison of various nanofiber production technologies. The current challenges and perspectives of nanofiber scaffolds for drug delivery are presented, and the future research directions of the field are also highlighted.

\section{Variety of Polymeric Biomaterials}

Over 200 polymers can be utilized to spin nanofibers; however, only those that are biocompatible and biodegradable have been utilized as biomaterials to load drugs for tissue engineering [17]. Table 1 presents various biocompatible and biodegradable polymers that have been used to produce nanofibers for different biomedical applications. Cellulose, chitosan, chitin and collagen are the major nature biopolymers; poly lactic-co-glycolic acid (PLGA), polyethylene oxide (PEO) and polycaprolactone (PCL) are popular synthetic biopolymers. Natural and synthetic polymeric biomaterials are usually composited to produce nanofiber scaffolds for various biomedical applications, as shown in Figure 1. Natural polymeric biomaterials are native extracellular matrixes (ECMs); however, they are very difficult to form into continuous nanofibers. Synthetic polymeric biomaterials are used to improve the spinnability and dimensional stability of nanofibers. In addition, the biodegradation rate of nanofibers also can be controlled by varying the ratio of nature biopolymers and synthetic biopolymers, so as to control the drug release rate during drug delivery. 
Table 1. Fibers from different polymeric biomaterials for biomedical applications.

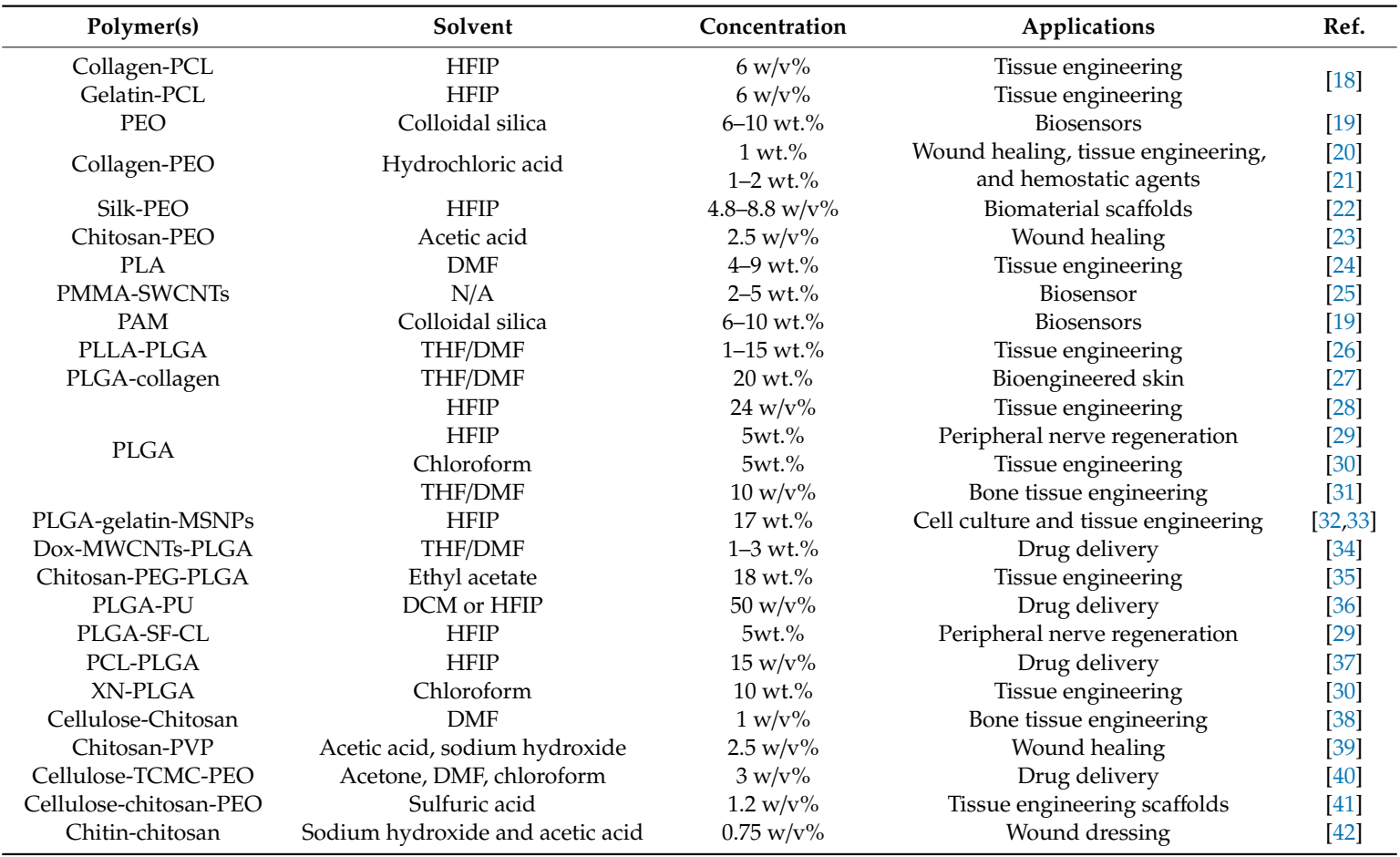

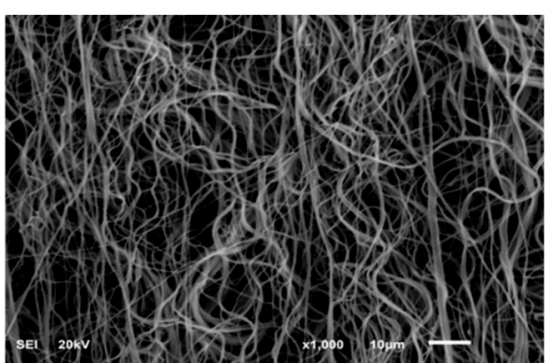

(a)

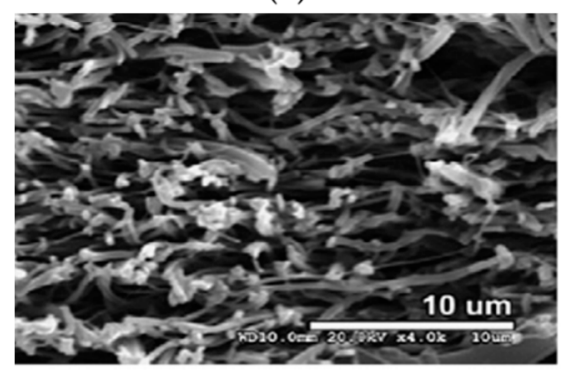

(c)

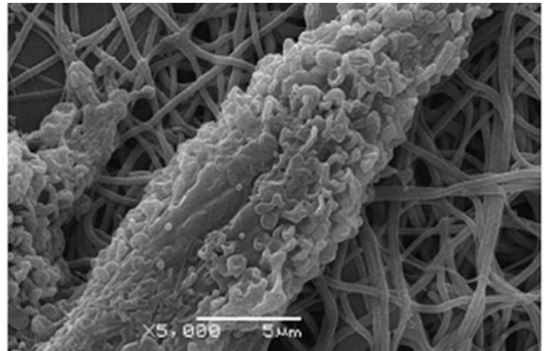

(b)

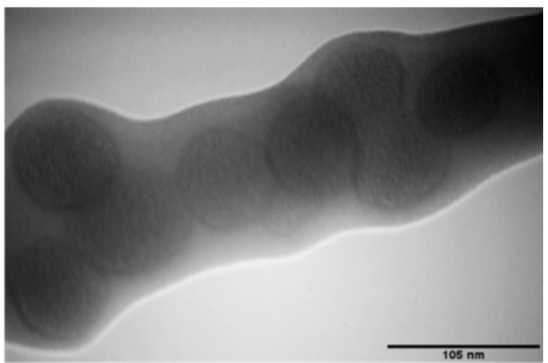

(d)

Figure 1. SEM images of different composite nanofibers for various biomedical applications: (a) chitosan-polyethylene oxide (PEO) composite nanofibers [43] (Copyright 2019, MDPI); (b) L929 cell seeded on carboxyethyl chitosan/polyvinyl alcohol (PVA) nanofibrous membrane after 48-h culture [44] (Copyright 2011, Elsevier); (c) cross-section of PCL/collagen nanofiber scaffolds [45] (Copyright 2009, Elsevier); (d) TEM image of highly aligned poly lactic-co-glycolic acid (PLGA)-gelatin nanofibers with 10 wt.\% mesoporous silica nanoparticles [33] (Copyright 2015, Elsevier). 


\subsection{Natural Polymeric Biomaterials}

\subsubsection{Cellulose}

Cellulose is a popular polysaccharide and exists throughout the world. Due to their excellent biodegradability and chemical resistance, cellulose nanofibers show a great potential for biomedical applications $[46,47]$. The process of cellulose is limited by the solubility of cellulose in common organic solutions, due to vast intermolecular and intramolecular hydrogen bonds [48]. Therefore, cellulose has to be dissolved into single or mixed solvents before producing nanofibers. Various solvents have been used to dissolve cellulose, including ethanol, water, chloroform, dioxin, $N, N$-dimethylacetamide (DMA), dimethylformamide (DMF) and dichloromethane (DCM) (cellulose is quite difficult to dissolve) [46,49-51]. Initially, cellulose fibers were produced by wet spinning, but, currently, cellulose nanofibers are usually fabricated via electrospinning [46]. Cellulose derivatives are also widely used to deliver drugs or growth factors in tissue engineering applications. Cellulose acetate (CA) is obtained from acetylating cellulose, the most abundant natural polymer [47]. CA has huge potential for drug delivery. CA fiber mats produced via electrospinning were utilized to release three ester prodrugs of naproxen [52] and to load tetracycline hydrochloride and slowly release the drug for antibacterial activity [48]. CA nanofibers also showed their antioxidant characteristics via loading 6-gingerol for transdermal drug delivery [53]. Ethyl cellulose (EC) was used as the shell layer of core-shell nanofibers to protect the core layer and release bioactive agents during in-vitro cell culture studies [54]. In addition, cellulose triacetate, methyl cellulose and hydroxypropyl cellulose were also investigated for tissue engineering applications [55-57].

\subsubsection{Chitin and Chitosan}

Chitin is a linear 1, 4-linked polymer composed of $N$-acetyl-D-glucosamine residues, which can be obtained from seafood wastes and invertebrate skeletons [58]. Chitin is one of the largest abundant natural polysaccharide polymers in the world [59]. It is also one of the most promising natural polymers for tissue engineering applications, due to its biocompatible, biodegradable, antibacterial, nontoxic, and adhesive properties [44]. Chitin and its derivatives have been prepared to produce various forms of materials (including nanofibers, membranes and sponges) for wound dressing and burn dressing. Chitin-based dressings could accelerate contraction of wounds, promote repairing of damaged tissues, and regulate secretion of inflammatory mediators. Chitin nanofibers have been seen as an ideal substitute for traditional inorganic nanofillers for drug delivery applications, not only because of their biodegradability and biocompatibility, but also their excellent mechanical properties. However, chitin cannot be dissolved into common organic solvents or diluted aqueous, and the weak solubility of chitin hinders its industrialization [60]. Therefore, finding a suitable dissolution system for chitin is essential for further extending the applications of chitin.

Chitosan is a linear polymer composed of $\beta$ (1-4) linked D-glucosamine units, which is derived from $N$-deacetylation of chitin. As a significant derivative of chitin, chitosan is also biodegradable, biocompatible and nontoxic. Moreover, due to its antibacterial and antifungal properties, chitosan has great potential for tissue engineering applications. Recently, chitosan-based nanofibers have been utilized as matrix molecules for drug delivery [61]. Their application in drug delivery is significantly influenced by the degree of acetylation and molecular weight because these properties influence hydrophobic ability and can change the drug encapsulation efficiency. although chitosan can hardly be dissolved in neutral aqueous solvents, its solubility improves with increasing acidic solvents because of its amino groups [62]. As a vehicle of drug delivery, the mucoadhesive ability of chitosan has attracted much attention. Chitosan has been used to load and deliver drugs through various epithelia, including buccal [63], ocular [64], intestinal [65], and nasal [66]. The spinnability of pure chitosan is poor; therefore, many synthetic polymers are used to composite with chitosan to produce chitosan-based nanofibers [67]. Chitosan cannot be dissolved into most organic solvents; therefore, various chitosan derivatives have been prepared to improve the encapsulation ability of hydrophobic 
drugs. For example, carboxylated chitosan (CCS) is used as a water-soluble chitosan to fabricate chitosan-based nanofibers for delivery of drugs in skin regeneration [68]. In addition, water-soluble chitosan could be used for wound healing applications, rather than being restricted by toxic or acidic solvents [69].

\subsubsection{Collagen}

Collagen is not only the primary structural element of ECM, but also the most abundant protein of the human body [45]. Collagen is organized into insoluble fibers to support tensile strength. For example, muscle fibers transmit forces, consume energy and protect tissues from external forces, due to numerous collagens in them. If collagen is insufficient, the tissue is weak and might rupture [70]. Moreover, collagen also provides biological cues to nearby cells and regulates various bio-functional responses [20]. The collagen family involves at least 30 different gene products and concentrates into over 20 collagen types. The molecular structure of these collagen types is the triple helical. Additionally, collagen types I, II and III are the most abundant fibrillar collagens in the human body [11]. Collagen has been applied into a large number of tissue engineering applications, due to its excellent properties in the ECM, low antigenicity, non-immunogenicity and cell compatibility [71]. Collagen was used in orthopedic surgeries as an implantable ECM to accelerate bone growth [72]. Extracted collagen is quite difficult to process into artificial nanofibers. Therefore, researchers usually dissolve collagen with other spinnable polymers into solvents and produce collagen composite nanofibers for drug delivery in tissue engineering. Collagen type I was coated on PCL-chitosan nanofiber to bind fiber scaffolds and as an agent for healing burn injuries during skin regeneration [73]. Collagen and PLLA were blended into HFIP and produced nanofibers via electrospinning as wound dressing [74]. Three-dimensional (3D) PLGA nanofiber scaffolds loaded with collagen I were utilized to promote primary hepatocyte function [75]. A novel collagen-mimetic peptide amphiphile has also been produced to make collagen-based nanofibers for tissue regeneration [76].

\subsubsection{Other Natural Polymeric Biomaterials}

Other natural polymeric biomaterials, such as silk fibroin, keratin, alginate, and chondroitin, are also broadly studied for drug delivery and tissue engineering. For example, silk fibroin is derived from cocoons, which is a promising biopolymer due to its excellent biocompatibility and low biodegradation rate in the human body [77]. Ang et al. produced silk fibroin composite nanofibers to deliver osteogenic marker genes, osteocalcin and alkaline phosphatase for bone tissue engineering [78]. For drug delivery applications, these biopolymers are frequently produced for implantation as porous nanofiber scaffolds or nanofiber membranes into nontoxic ending products in vivo.

However, the disadvantages of natural biopolymers include inconsistent compositions and weak mechanical strength [79]. Additionally, the kinetics of these natural biomaterials might be hard to control when the long-term responsive action is insufficient.

\subsection{Synthetic Polymeric Biomaterials}

\subsubsection{Poly Lactic-co-Glycolic Acid (PLGA)}

Poly lactic-co-glycolic acid (PLGA) is a co-polymer material from poly lactic acid (PLA) and poly glycolic acid (PGA) with different ratios, such as 75:25, 65:35, 50:50 and 25:75 [11]. The melting point and crystallinity degree of polymers are ultimately related to their molecular weight. The glass transition temperature of PLGA has been demonstrated to decrease with decreasing lactide content and molecular weight [80]. The mechanical strength of PLGA nanofibers is significantly influenced by their physical properties, including polydispersity index, ratio of poly lactic acid and poly glycolic acid, and molecular weight. These properties also impact the shape and size of PLGA production for delivery of drug and controlling the degradation rate [81]. PLGA is one of the most attractive synthetic polymers, and is frequently employed to prepare materials for drug delivery, due to its 
biocompatible, biodegradable and tunable mechanical properties. PLGA has been widely investigated and processed into any morphology for development of biomedical materials for delivery, control and release of bioactive agents, drugs and proteins in the academic community and industry. PLGA has been combined with other materials, including bioactive glass or ceramics, to improve biomimetic ability and accelerate bone regeneration. Porous silica nanoparticles are random loaded into PLGA nanofibers via the electrospinning method for improving mechanical properties in cell proliferation [32]. PLGA is widely dissolved into many common solvents, such as HFIP [32,37], DMF [30,34], THF [31], chloroform [75] and ethyl acetate [35], for drug delivery in biomedical applications. However, the potential residual toxic solvents might pose a negative influence for drug release and cell proliferation.

\subsubsection{Polycaprolactone (PCL)}

Polycaprolactone (PCL) has been widely explored due to its excellent properties (biocompatibility, biodegradation, non-toxicity, low melting point $\left(60^{\circ} \mathrm{C}\right)$ and semi-crystallinity) and low cost. In addition, PCL can be dissolved into many common solvents, such as HFIP, chloroform, acetic acid, methanol and dichloromethane $[37,82,83]$. Due to these advantages, PCL is frequently utilized to produce multi-functional nanofibers for drug delivery in tissue engineering applications. Some common solvents are usually mixed to combine PCL with hydrophilic drugs, because PCL is a hydrophobic biomaterial [8]. For example, PCL-gelatin composite nanofibers were used to load metronidazole for anti-infection of skin tissue regeneration [84]. Additionally, smooth, homogeneous and hydrophilic PCL-gelatin nanofibers were used to grow and proliferate human umbilical arterial smooth muscle cells. PCL has also been blended with chitosan to promote the biocompatible and hydrophilic properties of nanofibers to mimic ECM and guide cell proliferation $[85,86]$.

\subsubsection{Polyethylene Oxide (PEO)}

Polyethylene oxide (PEO) is a crystalline synthetic polymer with thermoplastic properties. It is a water-soluble polymer with a simple chemical formula, $\mathrm{H}-\left(\mathrm{OCH}_{2} \mathrm{CH}_{2}\right)_{\mathrm{n}}-\mathrm{OH}$. Compared with other water-soluble synthetic polymeric biomaterials, $\mathrm{PEO}$ is unique in its linear structure. This special linear structure represents an excellent polymer-solvent interaction in water. For nanofiber production, the molecular weight of PEO is usually between $300,000-7,000,000$. PEO is a particularly effective synthetic polymer for protein resistance because of its hydrophilicity [87]. Moreover, PEO is frequently employed into drug delivery due to its biocompatibility, biodegradability, and non-toxicity [88]. Qu et al. produced PEO nanofibers to deliver the targeted enzyme for meniscus repair [89]. Additionally, PEO could be used to improve dimensional stability of nanofiber meshes [90]. Sadri et al. blended PEO with chitosan to enhance the spinnability of chitosan for antimicrobial agents in wound healing [91].

\subsubsection{Other Synthetic Polymeric Biomaterials}

Other biocompatible and biodegradable synthetic polymers are also extensively studied for drug delivery in tissue engineering applications, such as PVA and PVP. Polyvinyl alcohol (PVA) is a water-soluble polymer and widely utilized by blending with other biopolymers. It has been combined with chitosan to enhance cell attachment and biocompatibility of the composite nanofibers [92]. Poly( $N$-vinylpyrrolidone) (PVP) is also a water-soluble polymer with low toxicity and chemical stability. PVP has been employed as a blood plasma substitute in drug delivery systems, due to its blood compatibility and physiological inactivity [93].

\section{Nanofiber Production Methods}

In order to develop a more effective and higher production rate method for fabrication of nanofibers, various kinds of nanofiber fabrication techniques have been researched, such as electrospinning, centrifugal spinning, airbrushing, wet spinning, simple freeze-drying and jet-rapid freezing. A great diversity of methodologies has encouraged a wide range of research on producing nanostructures with advantageous properties for a vast number of engineering applications $[15,94,95]$. 


\subsection{Electrospinning}

Electrospinning was used for fabricating continuous fibers, which was first patented and developed by Farmhals in 1934 [96]. In 1969, Taylor researched the shape of the droplet at the tip of the spinneret in the electric field, before the solution jet ejecting from the orifice of the spinneret [97]. Since then, the droplet is known as "Taylor cone", as shown in Figure 2. Electrospinning is currently the most significant technology for manufacturing polymer nanofibers [98].

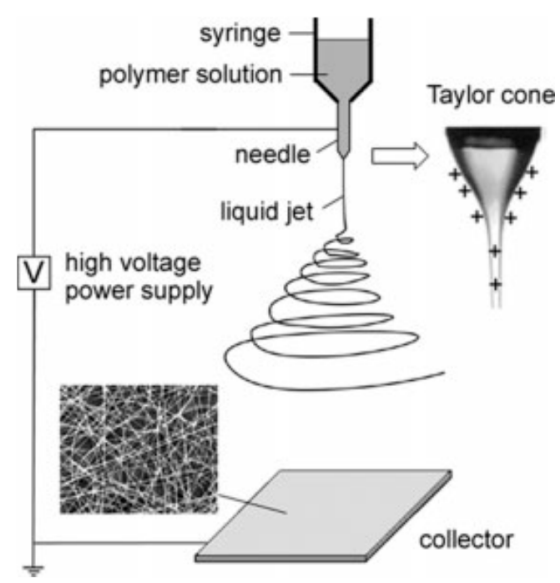

Figure 2. Schematic diagram of the basic setup for electrospinning process and Taylor cone [98] (Copyright 2004, John Wiley and Sons).

In electrospinning, a strong electric field (usually in the range of 5 to $30 \mathrm{kV}$ ) is generated between the polymer solution and a grounded collection plate by connecting the needle of the spinneret with a high voltage power, and connecting the collector with the ground (Figure 2). When a high voltage is supplied, the pendent drop of polymer liquid in the orifice of the spinneret becomes highly electrified and the induced charges are equally distributed on the surface of the spinneret, then the Taylor cone forms. Therefore, the liquid drop experiences electrostatic repulsion and Coulombic force at the same time [98]. There are various electrospinning parameters which can be divided into two categories: fluid intrinsic properties and operational conditions. The fluid intrinsic properties mainly include surface tension, solution viscosity, solution conductivity, molecular weight, and solvent evaporation rate. The operational conditions are voltage value, solution flow rate, nozzle diameter, collector distance, and spinning environment. The production rate of traditional electrospinning is too low to satisfy industrialization; therefore, various designs and equipment have been developed to improve productivity in the past decades.

Currently, the electrospinning system is mainly divided into two categories: needle electrospinning and needleless electrospinning. Needle electrospinning involves single-needle electrospinning (traditional electrospinning), multi-needle electrospinning and multiaxial electrospinning. The production rate of single-needle electrospinning is only around $0.1 \mathrm{~mL} / \mathrm{h}$; therefore, a straightforward method to improve the productivity is to increase the number of needles [99], and a waterfall geometry electrospinning setup with three needles was produced [100], as shown in Figure 3. However, in the multi-needle electrospinning system, strong electric field interference among the jets may reduce the production rate and form fibers of poor morphology and diameter distribution. Multiaxial electrospinning is designed to produce multiaxial nanofibers, even though the production rate is as low as traditional needle electrospinning, as shown in Figure 4. Various cross-section shapes of nanofibers can be produced via multiaxial electrospinning, to prevent bioactive agents from reaching the wound environment and load multiple drugs to improve the functionalization of nanofibers. 


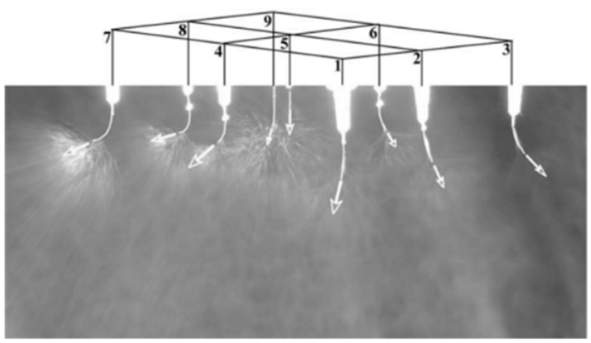

(a)

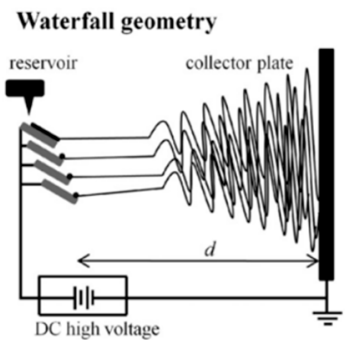

(b)

Figure 3. (a) Photograph of multi-jet electrospinning [99] (Copyright 2005, Elsevier); (b) schematic diagram of waterfall geometry electrospinning setup [100] (Copyright 2010, Elsevier).

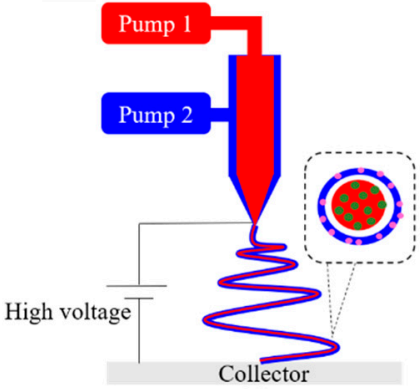

(a)

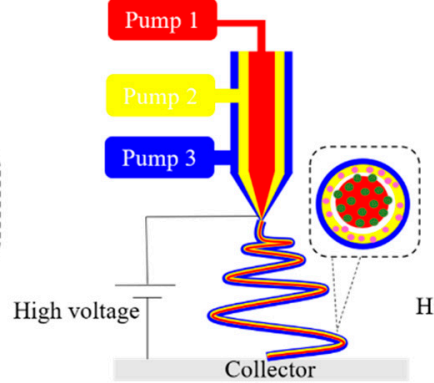

(b)

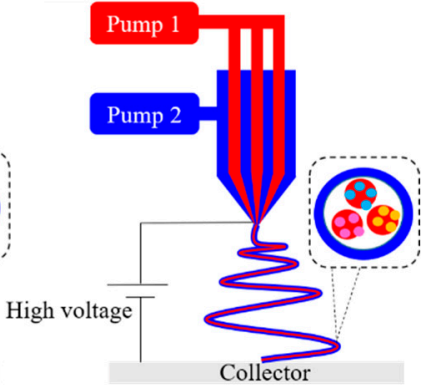

(c)

Figure 4. Schematic drawings of multiaxial electrospinning device for fabricating various components for encapsulating multiple drugs. (a) Coaxial electrospinning, (b) triaxial electrospinning, (c) islands-in-the-sea electrospinning.

A needleless electrospinning system dramatically improves the productivity of the electrospinning method, compared with needle electrospinning. In a needleless electrospinning system, Taylor cones are created on the surface of the polymer solution which cover the fiber generator [101]. For this reason, the inter-molecular interactions in the solution have to be strong enough to stabilize these Taylor cones, to make sure that Taylor cones can be stretched into ideal jets and collected on the collector wall [102]. In the setup, polymer jets had been created on the surface of a positively charged rotating roller electrode which was half-immersed in a polymer solution reservoir. As a further development of the technology, the rotating roller has been replaced by a stationary wire electrode (Figure 5). However, needleless electrospinning has its drawbacks in guided tissue regeneration (GTR), as the needleless system cannot fabricate multiaxial nanofibers to protect bioactive agents and control drug release. Hence, the drug delivery abilities of needless electrospinning are lower than of multiaxial nanofiber electrospinning.

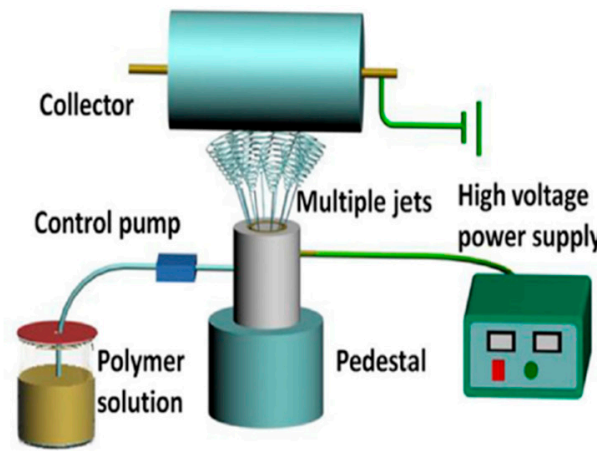

(a)

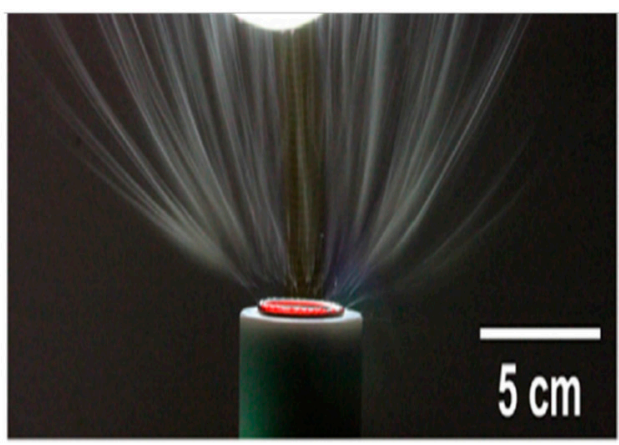

(b)

Figure 5. (a) Schematic diagram of a needleless electrospinning system, and (b) a photograph of the multiple jets forming in the needleless electrospinning process [103] (Copyright 2019, Elsevier). 
Electrospinning is the most popular nanotechnology. However, the low production rate (needle electrospinning) and high energy consumption limit the extensive range of commercial applications of nanofibers to take advantage of the unique properties. For these reasons, it is highly necessary to develop more effective approaches to produce nanofibers.

\subsection{Centrifugal Spinning}

Centrifugal spinning is an alternative technological method to fabricate polymer nanofibers at a high production rate but a low energy consumption, even though it is not a novel technology. This technique was evolved from a fabrication technology for cotton candy invented in 1897 [104]. Centrifugal spinning utilizes the centrifugal force to overcome the surface tension between the polymer solution and the nozzle wall, then the polymer jet is ejected and stretched by various forces (including centrifugal force, aerodynamic force, elastic viscous force and the Coriolis force), and the solvent continuously evaporates until the jet solidifies, and, finally, nanofibers are collected on a collector, as shown in Figure 6a. Similar to electrospinning, the parameters of centrifugal spinning can also be divided into two categories: fluid intrinsic properties and operational conditions. And these two nanofiber fabrication methods have some common parameters. The fluid intrinsic properties of centrifugal spinning are almost shared with electrospinning, except for solution conductivity. Therefore, the material choice of centrifugal spinning is broader than electrospinning because any polymer solution can be used to produce nanofibers via centrifugal spinning, even if the solution has no conductivity.

Centrifugal spinning is an emerging nanofiber fabrication method because it not only has a high production rate with a low cost, but can also produce multiaxial nanofibers to improve the functions of nanofibers [16,105]. Multiaxial structural nanofibers can be fabricated by different multiaxial nozzles, as shown in Figure 6b. This demonstrates that the centrifugal spinning method combines the advantages of needle electrospinning and needleless electrospinning. However, understanding the flow field of the technology and customizing the nanofiber structures for various applications are still to be further studied and investigated.

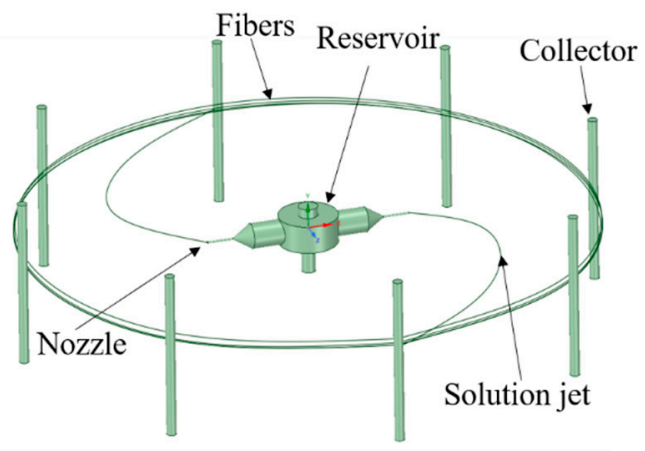

(a)

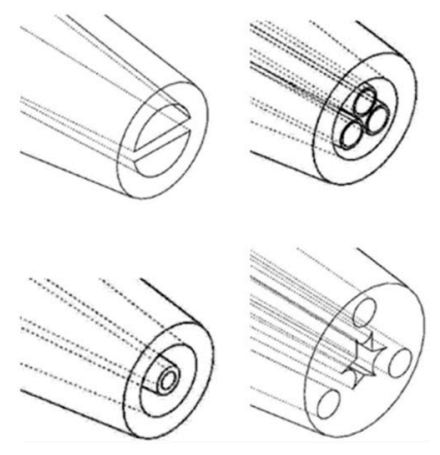

(b)

Figure 6. (a) Schematic of the centrifugal spinning process; (b) various cross-section shapes of nozzles for diverse morphologies of nanofibers in centrifugal spinning [106] (Copyright 2015, China Intellectual Property Office).

\subsection{Solution Blowing}

Solution blowing is a simple alternative method for nanofiber fabrication, due to the setup of this technology being simple, as shown in Figure 7. The solution blowing method is optimized from melt blowing [107]. In melt blowing system, polymer has to be melted at high temperatures, which significantly restricts its application in tissue engineering, due to the bioactive agents rapidly losing bioactivity in the environment. In order to overcome this disadvantage, polymer solution replaces melted polymer and the solution blowing method is introduced. Currently, non-woven nanofiber 
meshes for biomedical applications are frequently produced via solution blowing [108]. Singh et al. utilized solution blowing to fabricate core-shell PCL-PEO isotropic nanofibers for controlled sustainable release of dual drugs (bovine serum albumin and bFGF) [109]. However, how to produce aligned nanofibers in solution blowing system still needs to be solved, because numerous aligned artificial ECMs also have to be produced for respective applications.

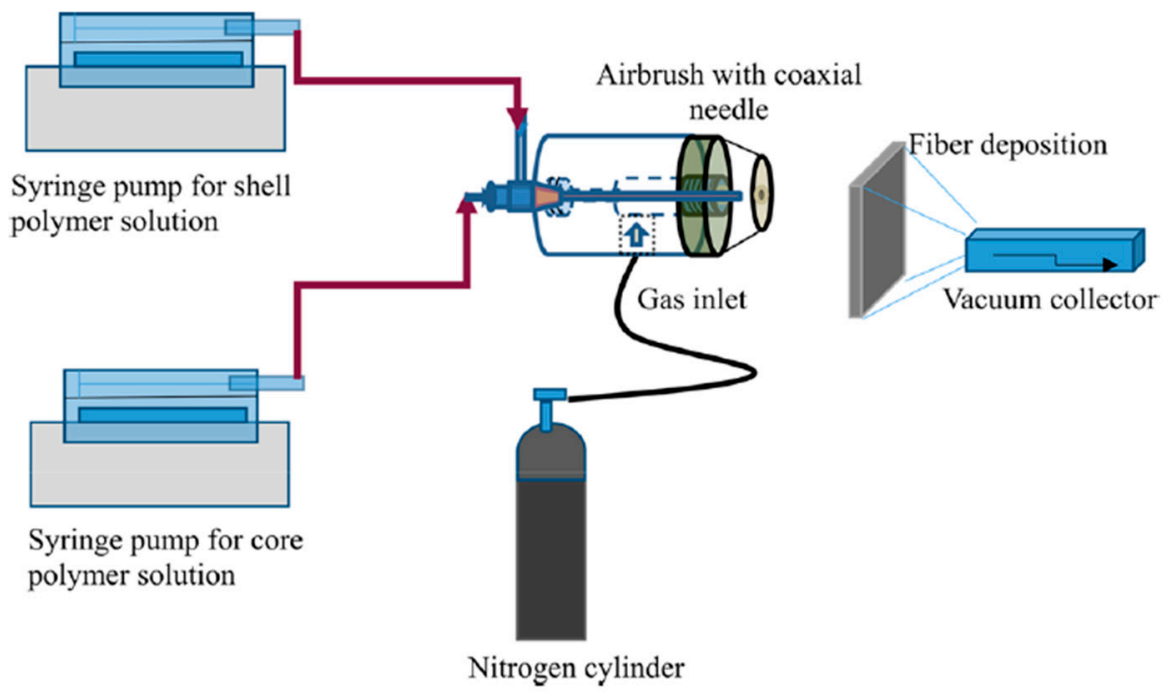

Figure 7. Schematic diagram of solution blowing spinning setup for single and core-shell structural nanofibers [109] (Copyright 2018, American Chemical Society).

\subsection{Other Nanofiber Fabrication Techniques}

Self-assembly is a process by which nanofibers are manufactured by holding molecules without external guidance or management. The technology of self-assembly can be divided into two types, intramolecular and intermolecular self-assembly, respectively $[76,110]$. In self-assembly approach, various mechanisms can be utilized to produce nanofibers depending on the polymer chemical structures. The mechanism of producing hydrogel is widely utilized to form network structural nanofibers via self-assembly of hydrogelator molecules.

Phase separation is another technique to fabricate polymeric nanofibers. The process of phase separation includes polymer dissolution, gelation, phase separation, solvent removal, and drying [26]. First of all, the polymer material is dissolved into a solvent, so as to form a homogeneous polymer solution. Then, the solution is sustained at the gelation time for several hours, so as to become nanofibrous matrix. Finally, nanofibers will be formed after evaporation of the solvent. It is clear that this kind of nanotechnology cannot produce aligned and multiaxial fibers; besides, the uniformity of nanofiber diameters cannot be guaranteed.

\section{Morphologies of Nanofibers}

The native ECM has a dynamic and 3D porous structure with a diameter at the range of $50-500 \mathrm{~nm}$. Therefore, the morphologies of artificial nanofibers for tissue engineering and drug delivery should be similar to native ECM, so as to provide an ideal microenvironment for cell adhesion and proliferation. The morphologies of nanofibers mainly involve fiber orientation and cross-section shape.

\subsection{Fiber Orientation}

The fiber orientation can be divided into isotropic and anisotropic fibers, as shown in Figure 8. Different orientation morphologies can be used to mimic different native ECMs for specific tissue regeneration. The orientations of isotropic nanofibers (or unaligned nanofibers) are chaotic and random, which means that the mechanical properties of this nanofiber are uniform in all orientations. 
This morphology of nanofibers can be employed to repair skin tissue in wound healing, as the ECM fibers of skin are also unaligned. For example, isotropic PCL nanofibers have been used to adsorb chitosan nanoparticles containing human granulocyte colony stimulating factor (G-CSF) for skin tissue regeneration [111]. Additionally, heparin mimetic peptide nanofibers with unaligned morphology dramatically promoted the tissue regeneration of burn injury [112]. Besides, anisotropic nanofibers imply different properties in different orientations. Anisotropic nanofibers also have a broad application in tissue engineering because they can be used to mimic aligned native ECM, such as muscle and nerve fibers. Aligned nanofibrous scaffolds possess unique electrical, optical, and mechanical properties and are excellent materials to guide cell growth with the desired anisotropy [17]. The mechanical properties of aligned collagen-PCL nanofiber scaffolds were similar to heart valve leaflet and cardiac muscle [113]. Zhang et. al fabricated gelatin/PLLA nanofibrous scaffolds and demonstrated that the anisotropic nanofibrous scaffolds were very valuable in corneal tissue engineering [114].

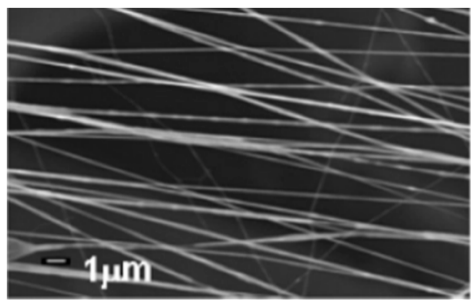

(a)

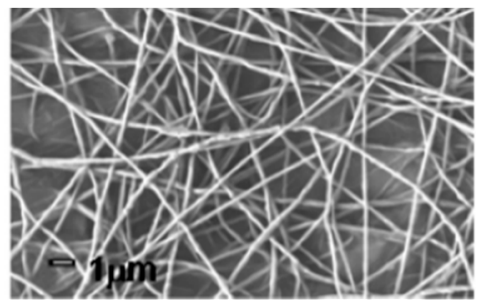

(b)

Figure 8. (a) SEM images of isotropic nanofibers and (b) anisotropic nanofibers [115] (Copyright 2007, American Chemical Society).

\subsection{Fiber Cross-Section}

The cross-sectional shapes of nanofibers are various, including single nanofibers and multiaxial nanofibers (such as coaxial nanofibers, hollow nanofibers and islands-in-the-sea nanofibers), as shown in Figure 9. Single nanofibers are the most common nanofibers for drug delivery in tissue engineering. As reported in Section 3, simple physical adsorption, nanoparticle assembly and chemical adsorption of drugs and bioactive agents are usually loaded on the surface of single nanofibers because the production process of single nanofibers is much easier than for other structural nanofibers. However, the disadvantages of single nanofibers are also obvious. For example, bioactive agents on the surface of single nanofibers will lose bioactivity rapidly in wound healing applications, due to the initial wound environment being severe for bioactive agents. In addition, it is very difficult to control the release rate of drugs or bioactive agents, when they are simply adsorbed on the surface of single nanofibers.

Multiaxial nanofibers are able to encapsulate the drug into the nanofiber core, so as to provide protection from the surrounding environment and control drug release [116]. Many common polymers (such as cellulose, chitosan, PVA and PEO) can be used to produce multiaxial nanofibers, and various drugs (including growth factors, DNA, antibodies and proteins) have been loaded into multiaxial nanofibers with different layers for different purposes [117-119]. Successful drug encapsulation is dependent on accurately distributing the drug into the fiber core. Drug encapsulation efficiency is significantly influenced by drug properties (like stability and solubility) and nanofiber morphologies [120]. Several nanofiber production methods have successfully been used to fabricate multiaxial nanofibers for drug delivery in tissue engineering, such as electrospinning [121], airbrush [109] and centrifugal spinning [105]. Multilayer nanofibers can load multi-drugs to satisfy multifunction of the nanofibers for tissue engineering. Core-shell nanofibers provided dual drug release profiles with adjustable doses in the second phase of tissue regeneration [122]. In order to investigate the potential advantages of multilayer nanofibers, other types of structures have also been produced, including triaxial structural nanofibers, hollow structural nanofibers and islands-in-the-sea nanofibers. Triaxial structural nanofibers have provided various drug release profiles for different model drugs (Keyacid uranine and Keyacid blue) separately loaded into the shell layer and core layer of the fiber, with a PCL intermediate layer 
for slowing release of the drug in the core layer [116]. Resveratrol and gentamycin sulfate have been encapsulated by PCL hollow nanofibers and exhibited a sustainable release without drug bursting [123]. Islands-in-the-sea (multichannel structural) nanofibers might have unique advantages, including independent channels for individual drugs and better mechanical stability, for vessel devices and multi-drug delivery in tissue engineering applications [124].

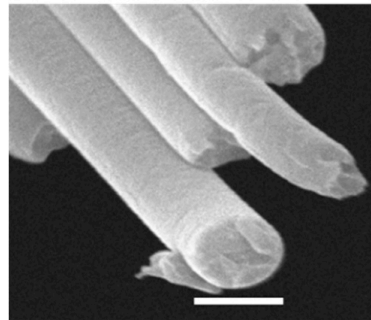

(a)

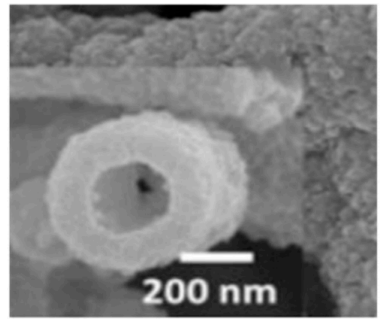

(c)

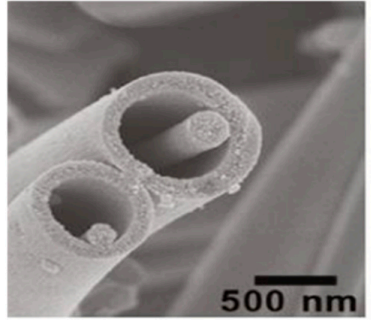

(b)

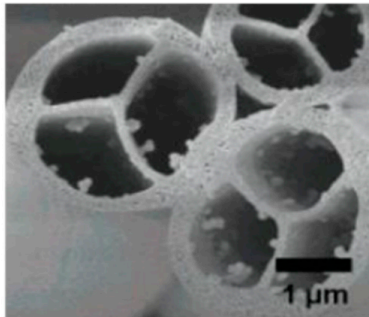

(d)

Figure 9. SEM images of various structural nanofibers: (a) single nanofibers, (b) core-shell nanofibers [125] (Copyright 2010, American Chemical Society); (c) hollow nanofibers [126] (Copyright 2017, Elsevier) and (d) islands-in-the-sea nanofibers [124] (Copyright 2007, American Chemical Society).

\section{Drug Loading in Nanofibers}

\subsection{Chemical Adsorption}

Chemical adsorption: drugs and bioactive agents are modified onto the surface of nanofibers through various functional groups, including carboxyl groups, amine groups, hydroxyl groups and hydrophilic linkers, as shown in Figure 10. In fact, the chemical adsorption method is more favored than the physical adsorption method in biomedical applications, due to the bioactive agents being covalently immobilized to nanofibers [127]. Therefore, these bioactive agents are not easily split away from the nanofibers during the incubation period. However, it is notable that the modified agents will incur partial inactivation upon the chemically modified covalent positions.
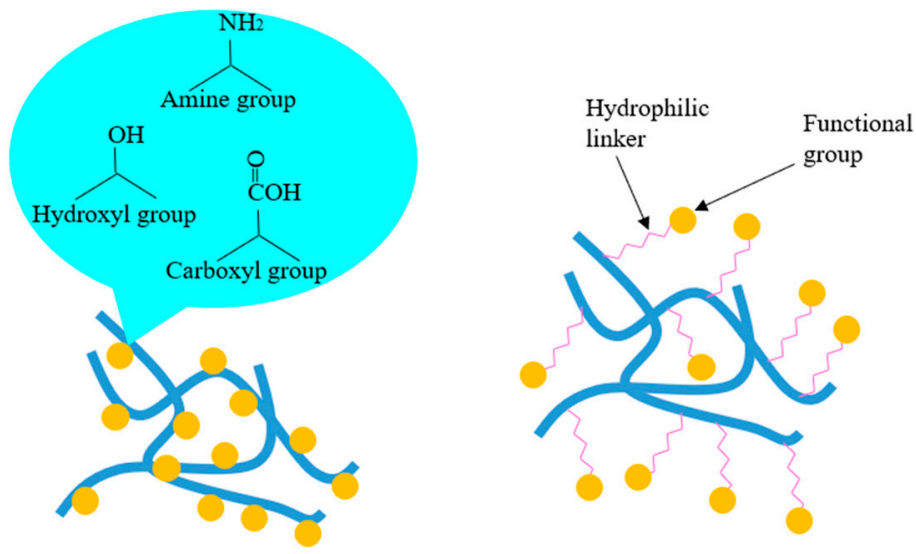

Figure 10. Common chemical adsorption of drug molecules onto the surface of nanofibers. 
Carboxyl groups have been frequently used to immobilize bioactive agents onto the surface of nanofibers. Carboxyl groups, for example, were successfully grafted onto the surface of PLGA, PLLA and PGA nanofiber scaffolds for conjugation with collagen, to improve cell adhesion and proliferation [128]. Carboxylic acid groups were employed to load rosuvastatin and heparin on the surface of cellulose acetate nanofibers for endovascular procedures [129]. Amine groups are also extensively used for covalent modification of polymeric nanofibers due to their high reactivity. Epidermal growth factor (EGF) has been chemically modified onto the surface of polymeric composite nanofibers for promoting the effect on the wound healing process [130]. Gold nanoparticles-SBA-15 composite has been bonded with Schiff bases via amine groups for improving the stability of biomaterials [131]. Hydroxyl groups are another kind of significant functional group, which also have been widely employed for chemical adsorption of drugs and bioactive agents. Hydroxyl groups of mesoporous silica nanoparticles (MSNPs) strongly interact with the nitrogenous groups of gelatin and the functional groups of PLGA to form a strong intermolecular network between those biomaterials for cell attachment and proliferation in wound healing [32,33].

However, direct modification of drug molecules on the surface of nanofibers might exhibit some limitations for cell attachment and proliferation. For example, cells cannot easily recognize the modified bioactive agents, as these agents are not entirely exposed to cells. Therefore, hydrophilic linkers are introduced to combine bioactive agents and nanofibers for promotion of cellular recognition. For example, EGF has been chemically modified onto the surface of amine-terminated block polymer composite nanofibers via polyethylene glycol (PEG) linkers [132].

\subsection{Physical Adsorption}

Currently, there are mainly three methods for physical adsorption of drugs in nanofibers or on the surface of nanofibers: simple physical adsorption, nanoparticle assembly, and multilayer assembly, as shown in Figure 11.

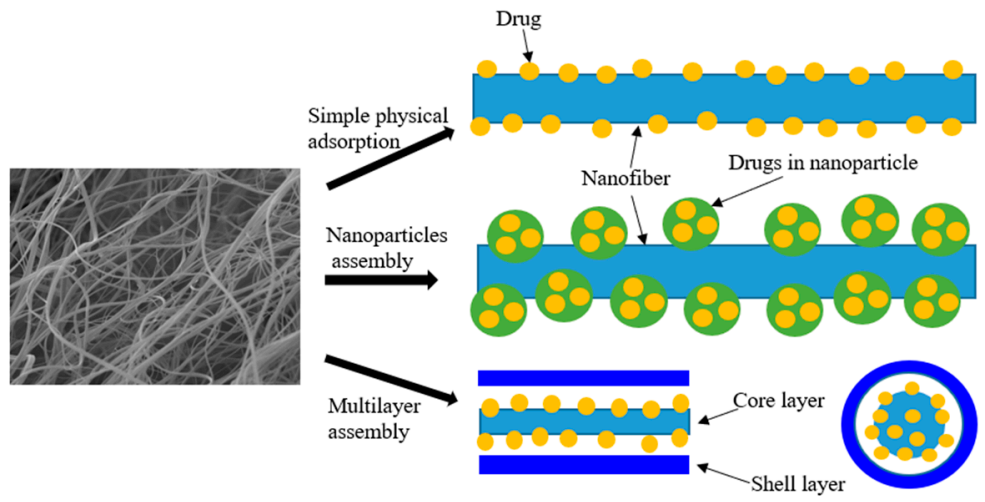

Figure 11. Three different physical adsorptions of drugs into nanofibers.

Simple physical adsorption: nanofibers have an extremely high porosity and surface area, allowing for a great number of drugs to be adsorbed on the surface of nanofibers. This is the simplest method for the delivery of drug via nanofibers, which can be used for burst release of drugs from the surface of nanofibers. PCL-gum tragacanth-curcumin nanofibers have been produced via dissolving curcumin into PCL-gum tragacanth solution, for preventing bacterial infection within a few hours during wound healing [133]. Heparin was successfully loaded on the surface of PEO/PLGA composite nanofibers by electrospinning [134]. In addition, anti-adhesion barrier application also requires loading drugs on the nanofiber surface, due to the adhesion between internal tissues often occurring after surgery [135].

Nanoparticles assembly: drugs are encapsulated into polymer nanoparticles, before these nanoparticles are adsorbed on the nanofibers. This method can effectively promote the drug loading capacity [136]. PVP nanofiber meshes containing silver nanoparticles have improved antibacterial properties in wound dressing [137]. Moreover, combining nanofibers and polymeric nanoparticles 
can enhance the multi-functional performance of nanoparticle-on-nanofiber structures [138]. Vascular endothelial growth factor (VEGF) has been relatively rapidly released on the surface of chitosan-PEO nanofibers, while platelet-derived growth factor-BB (PDGF-BB) is sustainably released from PLGA nanoparticles within the nanofibers [23]. A nanoparticle-on-nanofiber structure is a relatively stable system, which provides a one-step surface modification approach for drug loading.

Multilayer assembly: coaxial and triaxial micro-nano fibers with unique features (including reinforced core and hollow structure) can be utilized to sequester stimulants in different compartments and control the release of various drugs through changing drug positions and thickness of layers [8]. This drug delivery method has great potential for biomedical applications due to the generalization of any complex structure and the possibility of utilizing any composition for the core layer. For example, plasmid DNA has been embedded into the core layer of core-shell nanofibers for preventing enzyme attack before being released [139]. In addition, many bioactive agents have also been loaded into multilayer nanofibers. For instance, bovine serum albumin and basic fibroblast growth factor (bFGF) enjoyed sustained release from PCL-PEO composite core-shell structural nanofibers [109]. Notably, the thickness of multilayer fibrous structure also impact the drug release profile.

\section{Drug Release from Nanofibers}

Drugs or bioactive molecules are transported through the drug delivery system, which is controlled by the random movement of drug molecules and actuated by chemical potential gradients. A classical drug release in nanofibers refers to the drug being transported from its initial position in nanofibers to the outer surface of the nanofibers; then, the drug is released into its surroundings [140]. Additionally, drugs could be released through nanofibrous biomaterials by the matrix erosion effect, which results in porous formation. This section briefly discusses the selected examples of drug release mechanisms based on nanofibrous biomaterials. The mechanisms of drug release in nanofibers depend on drug diffusion, polymer nanofiber biodegradation, and nanofiber erosion [141].

\subsection{Drug Diffusion}

Drug molecules could be transported from nanofibers via diffusion through pores of nanofibers. It is known that nanofibers are highly porous; when nanofibers are filled with liquid, drug molecules randomly move through liquid-filled pores due to them being driven by the chemical potential gradients [142]. As time goes on, the size of pores becomes larger and more pores appear due to the degradable properties of the biomaterial matrix. More water will be immediately absorbed by porous nanofibers with pore size increasing, because the water absorption process is faster than drug movement [143]. Eventually, the drug release rate is increased. Drug molecules could also diffuse out from polymeric nanofibers because of their permeability and thickness [144]. In nondegradable matrix, diffusion is the major factor for drug release. Osmotic pumping is another approach to transport drug molecules via liquid-filled pores. Osmotic pressure drives the influx of liquid; as a result, drug molecules are diffused into surroundings by the force $[145,146]$.

\subsection{Nanofiber Erosion}

The erosion of nanofibers can be divided into surface erosion and bulk erosion. Surface erosion means that the polymeric nanofibers degrade from the surface by slowly reducing the size from the outside towards the inside [147]. Surface erosion is an ideal drug release mechanism for drug delivery application, due to the erosion kinetics being controllable as well as reproducible. It is notable that surface erosion occurs when the polymeric nanofiber erosion rate is higher than the liquid penetration rate into the bulk nanofibers [148]. Besides, bulk erosion occurs when the liquid penetration rate is higher than the polymeric nanofiber erosion rate. Therefore, bulk erosion is similar to hydrolyzing the polymeric nanofibers. Compared with surface erosion, bulk erosion is hard to control and the drug molecules cannot be protected from the environment [147]. 


\subsection{Drug Release Profile}

The models of various drug release profiles are shown in Figure 12. A zero-order release model is an ideal profile for drug release-rate-controlling. It means that the drug release rate is constant at any moment during the period of release. A controlled drug release system can not only provide temporal and spatial control of drug release, but also protect the drugs or bioactive molecules with therapeutic efficiency. Designed drug delivery formulations can be used to improve drug efficiency so as to minimize drug dose in patients.

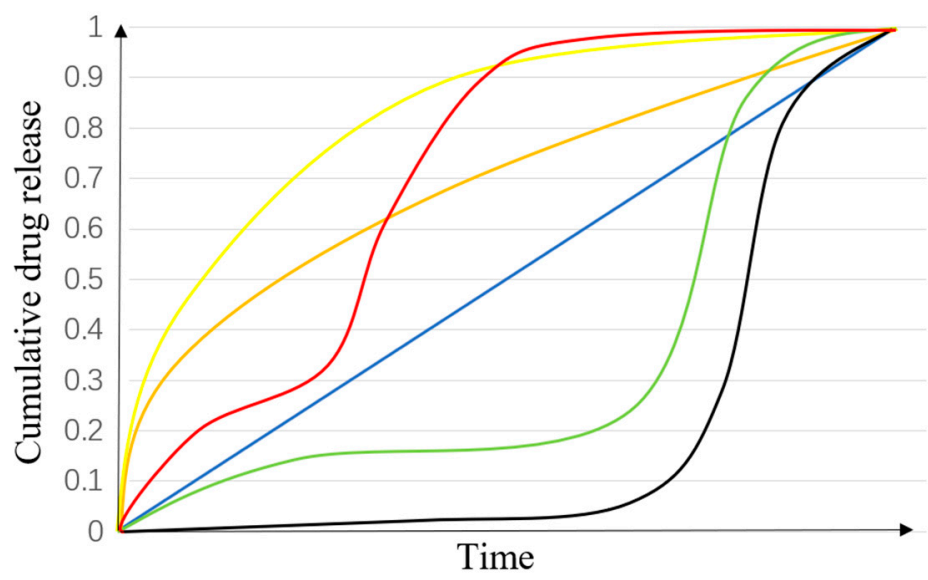

Figure 12. Different drug release profiles. Red: tri-phasic release with a short phase II; yellow: burst release and a quick phase II; blue: a zero-order release; orange: burst release with a zero-order release; green: a classical tri-phasic release; black: a classical bi-phasic, which is similar to a tri-phase without the burst release.

However, the most common drug release is a tri-phasic profile, and it sometimes represents a bi-phasic [142]. In a classical tri-phasic, phase I is often described as a burst release, which usually involves non-capsulation of drug molecules on the surface of the nanofibers; phase II usually shows a slow release, which is dominated by slow drug diffusion; phase III will be a faster release because of nanofiber erosion, compared with phase II. For example, PLGA-based nanofiber is an excellent biodegradable polymer material with a typical tri-phasic profile [142]. In PLGA micro/nano systems, polymer concentration and the morphology of the nanofibers are the key parameters in controlling drug release in phase I and II, and the drug release in phase III is determined by the degradation rate [149]. The drug release profiles of polymeric nanofibers are dependent on their individual physicochemical properties; therefore, the drug release profile needs to be studied for each polymeric matrix [141].

\section{Conclusions and Future Prospects}

Functional polymeric nanofibrous biomaterials are a critical class of artificial ECM for drug delivery in biomedical applications. Biomaterials from different polymers have been employed to load various drugs and produce multi-functional nanofibers. In order to control drug release rate while maintaining the bioactivity of agents, many approaches to adsorbing drugs have been investigated. Multiaxial nanofibers might be the best method for loading multiple drugs and delivering them with controllable release, because different drugs can be encapsulated into different layers to satisfy the multi-functionalization of nanofibers. The development of nanofiber production technology also has improved dramatically, and various methods are employed to fabricate multiaxial nanofibers with multiple functions for drug delivery. However, no technology has been used to produce multi-functional nanofibers for drug delivery at an industrial scale.

In the future, the mass, stable, and efficient production of multi-functional nanofibrous biomaterials should be the main the focus of technology development to translate the advanced nanofibers from the laboratories to industry implementation and eventually to clinical application. In addition, further 
studies should focus on combining nanofiber production and 3D printing technology. Therefore, the produced nanofibers can mimic both the micro and macro structures of different native ECMs, so as to apply functional nanofibers into individual tissues effectively and improve the functions of nanofibers in biomedical applications.

Author Contributions: Z.L. and L.K. conceived the concept of the review article and prepared the content outline. Z.L., Y.D., F.S., P.L. and Y.L. contributed to the review writing for different sections. S.M. and L.K. supervised the writing of this review paper and guided the major review and editing of the manuscript. All authors have read and agreed to the published version of the manuscript.

Funding: This work was supported by Science and Technology Program of Hubei Province (No. 2018AAA036), National Natural Science Foundation of China (No. 51175385) and Central Public-interest Scientific Institution Basal Research Fund for Innovative Research Team Program of CATAS (No. 1630122017009).

Acknowledgments: This work was performed in part at the Deakin Hub in the Victorian Node of the Australian National Fabrication Facility (ANFF).

Conflicts of Interest: The authors declare no conflict of interest.

\section{References}

1. Ketabchi, N.; Naghibzadeh, M.; Adabi, M.; Esnaashari, S.S.; Faridi-Majidi, R. Preparation and optimization of chitosan/polyethylene oxide nanofiber diameter using artificial neural networks. Neural Comput. Appl. 2017, 28, 3131-3143. [CrossRef]

2. Zhang, S.; Tang, N.; Cao, L.; Yin, X.; Yu, J.; Ding, B. Highly Integrated Polysulfone/Polyacrylonitrile/ Polyamide-6 Air Filter for Multilevel Physical Sieving Airborne Particles. ACS Appl. Mater. Interfaces 2016, 8, 29062-29072. [CrossRef] [PubMed]

3. Yanilmaz, M.; Lu, Y.; Li, Y.; Zhang, X. $\mathrm{SiO}_{2}$ /polyacrylonitrile membranes via centrifugal spinning as a separator for Li-ion batteries. J. Power Sources 2015, 273, 1114-1119. [CrossRef]

4. Marano, S.; Barker, S.A.; Raimi-Abraham, B.T.; Missaghi, S.; Rajabi-Siahboomi, A.; Craig, D.Q.M. Development of micro-fibrous solid dispersions of poorly water-soluble drugs in sucrose using temperature-controlled centrifugal spinning. Eur. J. Pharm. Biopharm. 2016, 103, 84-94. [CrossRef] [PubMed]

5. Cheng, J.; Jun, Y.; Qin, J.H.; Lee, S.H. Electrospinning versus microfluidic spinning of functional fibers for biomedical applications. Biomaterials 2017, 114, 121-143. [CrossRef] [PubMed]

6. Habibi, N.; Kamaly, N.; Memic, A.; Shafiee, H. Self-assembled peptide-based nanostructures: Smart nanomaterials toward targeted drug delivery. Nano Today 2016, 11, 41-60. [CrossRef]

7. Zamani, M.; Prabhakaran, M.P.; Ramakrishna, S. Advances in drug delivery via electrospun and electrosprayed nanomaterials. Int. J. Nanomed. 2013, 8, 2997-3017.

8. Khalf, A.; Madihally, S.V. Recent advances in multiaxial electrospinning for drug delivery. Eur. J. Pharm. Biopharm. Off. J. Arb. Fur Pharm. Verfahr. 2017, 112, 1-17. [CrossRef]

9. Rasouli, R.; Barhoum, A.; Bechelany, M.; Dufresne, A. Nanofibers for Biomedical and Healthcare Applications. Macromol. Biosci. 2019, 19, 27.

10. Figueiredo, P.; Lintinen, K.; Kiriazis, A.; Hynninen, V.; Liu, Z.H.; Bauleth-Ramos, T.; Rahikkala, A.; Correia, A.; Kohout, T.; Sarmento, B.; et al. In vitro evaluation of biodegradable lignin-based nanoparticles for drug delivery and enhanced antiproliferation effect in cancer cells. Biomaterials 2017, 121, 97-108. [CrossRef]

11. Barnes, C.P.; Sell, S.A.; Boland, E.D.; Simpson, D.G.; Bowlin, G.L. Nanofiber technology: Designing the next generation of tissue engineering scaffolds. Adv. Drug Deliv. Rev. 2007, 59, 1413-1433. [CrossRef] [PubMed]

12. Chen, S.X.; Li, R.Q.; Li, X.R.; Xie, J.W. Electrospinning: An enabling nanotechnology platform for drug delivery and regenerative medicine. Adv. Drug Deliv. Rev. 2018, 132, 188-213. [CrossRef] [PubMed]

13. Pant, B.; Park, M.; Park, S.J. Drug Delivery Applications of Core-Sheath Nanofibers Prepared by Coaxial Electrospinning: A Review. Pharmaceutics 2019, 11, 305. [CrossRef]

14. Wang, S.; Ju, J.P.; Wu, S.X.; Lin, M.; Sui, K.Y.; Xia, Y.Z.; Tan, Y.Q. Electrospinning of biocompatible alginate-based nanofiber membranes via tailoring chain flexibility. Carbohydr. Polym. 2020, 230, 115665. [CrossRef]

15. Zhang, X.; Lu, Y. Centrifugal Spinning: An Alternative Approach to Fabricate Nanofibers at High Speed and Low Cost. Polym. Rev. 2014, 54, 677-701. [CrossRef] 
16. Vocetkova, K.; Buzgo, M.; Sovkova, V.; Rampichova, M.; Staffa, A.; Filova, E.; Lukasova, V.; Doupnik, M.; Fiori, F.; Amler, E. A comparison of high throughput core-shell 2D electrospinning and 3D centrifugal spinning techniques to produce platelet lyophilisate-loaded fibrous scaffolds and their effects on skin cells. RSC Adv. 2017, 7, 53706-53719. [CrossRef]

17. Kong, B.; Mi, S.L. Electrospun Scaffolds for Corneal Tissue Engineering: A Review. Materials 2016, 9, 614. [CrossRef] [PubMed]

18. Badrossamay, M.R.; Balachandran, K.; Capulli, A.K.; Golecki, H.M.; Agarwal, A.; Goss, J.A.; Kim, H.; Shin, K.; Parker, K.K. Engineering hybrid polymer-protein super-aligned nanofibers via rotary jet spinning. Biomaterials 2014, 35, 3188-3197. [CrossRef]

19. Lim, J.M.; Yi, G.R.; Moon, J.H.; Heo, C.J.; Yang, S.M. Superhydrophobic films of electrospun fibers with multiple-scale surface morphology. Langmuir 2007, 23, 7981-7989. [CrossRef]

20. Huang, L.; Apkarian, R.P.; Chaikof, E.L. High-resolution analysis of engineered type I collagen nanofibers by electron microscopy. Scanning 2001, 23, 372-375. [CrossRef]

21. Huang, L.; Nagapudi, K.; Apkarian, R.P.; Chaikof, E.L. Engineered collagen-PEO nanofibers and fabrics. J. Biomater. Sci. Polym. Ed. 2001, 12, 979-993. [CrossRef] [PubMed]

22. Jin, H.J.; Fridrikh, S.V.; Rutledge, G.C.; Kaplan, D.L. Electrospinning Bombyx mori Silk with Poly(ethylene oxide). Biomacromolecules 2002, 3, 1233-1239. [CrossRef] [PubMed]

23. Xie, Z.W.; Paras, C.B.; Weng, H.; Punnakitikashem, P.; Su, L.C.; Vu, K.; Tang, L.P.; Yang, J.; Nguyen, K.T. Dual growth factor releasing multi-functional nanofibers for wound healing. Acta Biomater. 2013, 9, 9351-9359. [CrossRef] [PubMed]

24. Golecki, H.M.; Yuan, H.; Glavin, C.; Potter, B.; Badrossamay, M.R.; Goss, J.A.; Phillips, M.D.; Parker, K.K. Effect of solvent evaporation on fiber morphology in rotary jet spinning. Langmuir 2014, 30, 13369-13374. [CrossRef]

25. Han, L.; Andrady, A.L.; Ensor, D.S. Chemical sensing using electrospun polymer/carbon nanotube composite nanofibers with printed-on electrodes. Sens. Actuators B Chem. 2013, 186, 52-55. [CrossRef]

26. Ma, P.X.; Zhang, R.Y. Synthetic nano-scale fibrous extracellular matrix. J. Biomed. Mater. Res. 1999, 46, 60-72. [CrossRef]

27. Sadeghi, A.R.; Nokhasteh, S.; Molavi, A.M.; Khorsand-Ghayeni, M.; Naderi-Meshkin, H.; Mahdizadeh, A. Surface modification of electrospun PLGA scaffold with collagen for bioengineered skin substitutes. Mater. Sci. Eng. C Mater. Biol. Appl. 2016, 66, 130-137. [CrossRef]

28. Gao, J.; Huang, G.; Liu, G.; Liu, Y.; Chen, Q.; Ren, L.; Chen, C.; Ding, Z. A biodegradable antibiotic-eluting PLGA nanofiber-loaded deproteinized bone for treatment of infected rabbit bone defects. J. Biomater. Appl. 2016, 31, 241-249. [CrossRef]

29. Zhang, M.; Lin, W.; Li, S.; Shi, X.-Y.; Liu, Y.; Guo, Q.; Huang, Z.; Li, L.; Wang, G.-L. Application and Effectiveness Evaluation of Electrostatic Spinning PLGA-Silk Fibroin-Collagen Nerve Conduits for Peripheral Nerve Regeneration. J. Nanosci. Nanotechnol. 2016, 16, 9413-9420. [CrossRef]

30. Qiao, T.; Jiang, S.; Song, P.; Song, X.; Liu, Q.; Wang, L.; Chen, X. Effect of blending HA-g-PLLA on xanthohumol-loaded PLGA fiber membrane. Colloids Surf. B Biointerfaces 2016, 146, 221-227. [CrossRef]

31. Sanaei-Rad, P.; Jafarzadeh Kashi, T.-S.; Seyedjafari, E.; Soleimani, M. Enhancement of stem cell differentiation to osteogenic lineage on hydroxyapatite-coated hybrid PLGA/gelatin nanofiber scaffolds. Biol. J. Int. Assoc. Biol. Stand. 2016, 44, 511-516. [CrossRef] [PubMed]

32. Mehrasa, M.; Asadollahi, M.A.; Nasri-Nasrabadi, B.; Ghaedi, K.; Salehi, H.; Dolatshahi-Pirouz, A.; Arpanaei, A. Incorporation of mesoporous silica nanoparticles into random electrospun PLGA and PLGA/gelatin nanofibrous scaffolds enhances mechanical and cell proliferation properties. Mater. Sci. Eng. C Mater. Biol. Appl. 2016, 66, 25-32. [CrossRef]

33. Mehrasa, M.; Asadollahi, M.A.; Ghaedi, K.; Salehi, H.; Arpanaei, A. Electrospun aligned PLGA and PLGA/gelatin nanofibers embedded with silica nanoparticles for tissue engineering. Int. J. Biol. Macromol. 2015, 79, 687-695. [CrossRef] [PubMed]

34. Qi, R.-L.; Tian, X.-j.; Guo, R.; Luo, Y.; Shen, M.-W.; Yu, J.-Y.; Shi, X.-Y. Controlled release of doxorubicin from electrospun MWCNTs/PLGA hybrid nanofibers. Chin. J. Polym. Sci. 2016, 34, 1047-1059. [CrossRef]

35. Bienek, D.R.; Hoffman, K.M.; Tutak, W. Blow-spun chitosan/PEG/PLGA nanofibers as a novel tissue engineering scaffold with antibacterial properties. J. Mater. Sci. -Mater. Med. 2016, 27, 1-10. [CrossRef] [PubMed] 
36. Blakney, A.K.; Simonovsky, F.I.; Suydam, I.T.; Ratner, B.D.; Woodrow, K.A. Rapidly Biodegrading PLGA-Polyurethane Fibers for Sustained Release of Physicochemically Diverse Drugs. ACS Biomater. Sci. Eng. 2016, 2, 1595-1607. [CrossRef]

37. Chou, S.-F.; Woodrow, K.A. Relationships between mechanical properties and drug release from electrospun fibers of PCL and PLGA blends. J. Mech. Behav. Biomed. Mater. 2016, 65, 724-733. [CrossRef]

38. Peschel, D.; Zhang, K.; Fischer, S.; Groth, T. Modulation of osteogenic activity of BMP-2 by cellulose and chitosan derivatives. Acta Biomater. 2012, 8, 183-193. [CrossRef]

39. Rasool, A.; Ata, S.; Islam, A. Stimuli responsive biopolymer (chitosan) based blend hydrogels for wound healing application. Carbohydr. Polym. 2019, 203, 423-429. [CrossRef]

40. Esmaeili, A.; Haseli, M. Optimization, synthesis, and characterization of coaxial electrospun sodium carboxymethyl cellulose-graft-methyl acrylate/poly(ethyleneoxide) nanofibers for potential drug-delivery applications. Carbohydr. Polym. 2017, 173, 645-653. [CrossRef]

41. Ridolfi, D.M.; Lemes, A.P.; de Oliveira, S.; Justo, G.Z.; Palladino, M.V.; Duran, N. Electrospun poly(ethylene oxide)/chitosan nanofibers with cellulose nanocrystals as support for cell culture of 3T3 fibroblasts. Cellulose 2017, 24, 3353-3365. [CrossRef]

42. Tabuchi, R.; Azuma, K.; Izumi, R.; Tanou, T.; Okamoto, Y.; Nagae, T.; Iohara, D.; Uekama, K.; Otagiri, M.; Hirayama, F.; et al. Biomaterials based on freeze dried surface-deacetylated chitin nanofibers reinforced with sulfobutyl ether beta-cyclodextrin gel in wound dressing applications. Int. J. Pharm. 2016, 511, 1080-1087. [CrossRef] [PubMed]

43. Li, Z.; Mei, S.; Dong, Y.; She, F.; Kong, L. High Efficiency Fabrication of Chitosan Composite Nanofibers with Uniform Morphology via Centrifugal Spinning. Polymers 2019, 11, 1550. [CrossRef] [PubMed]

44. Jayakumar, R.; Prabaharan, M.; Kumar, P.T.S.; Nair, S.V.; Tamura, H. Biomaterials based on chitin and chitosan in wound dressing applications. Biotechnol. Adv. 2011, 29, 322-337. [CrossRef] [PubMed]

45. Sell, S.A.; McClure, M.J.; Garg, K.; Wolfe, P.S.; Bowlin, G.L. Electrospinning of collagen/biopolymers for regenerative medicine and cardiovascular tissue engineering. Adv. Drug Deliv. Rev. 2009, 61, 1007-1019. [CrossRef] [PubMed]

46. Kim, C.W.; Kim, D.S.; Kang, S.Y.; Marquez, M.; Joo, Y.L. Structural studies of electrospun cellulose nanofibers. Polymer 2006, 47, 5097-5107. [CrossRef]

47. Puls, J.; Wilson, S.A.; Hölter, D. Degradation of Cellulose Acetate-Based Materials: A Review. J. Polym. Environ. 2010, 19, 152-165. [CrossRef]

48. Gouda, M.; Hebeish, A.A.; Aljafari, A.I. Synthesis and characterization of novel drug delivery system based on cellulose acetate electrospun nanofiber mats. J. Ind. Text. 2014, 43, 319-329. [CrossRef]

49. Zhang, L.F.; Menkhaus, T.J.; Fong, H. Fabrication and bioseparation studies of adsorptive membranes/felts made from electrospun cellulose acetate nanofibers. J. Membr. Sci. 2008, 319, 176-184. [CrossRef]

50. Kim, C.W.; Frey, M.W.; Marquez, M.; Joo, Y.L. Preparation of submicron-scale, electrospun cellulose fibers via direct dissolution. J. Polym. Sci. Part B Polym. Phys. 2005, 43, 1673-1683. [CrossRef]

51. Kulpinski, P. Cellulose nanofibers prepared by the N-methylmorpholine-N-oxide method. J. Appl. Polym. Sci. 2005, 98, 1855-1859. [CrossRef]

52. Wu, X.M.; Branford-White, C.J.; Zhu, L.M.; Chatterton, N.P.; Yu, D.G. Ester prodrug-loaded electrospun cellulose acetate fiber mats as transdermal drug delivery systems. J. Mater. Sci. Mater. Med. 2010, 21, 2403-2411. [CrossRef]

53. Chantarodsakun, T.; Vongsetskul, T.; Jangpatarapongsa, K.; Tuchinda, P.; Uamsiri, S.; Bamrungcharoen, C.; Kumkate, S.; Opaprakasit, P.; Tangboriboonrat, P. 6-Gingerol-loaded cellulose acetate electrospun fibers as a topical carrier for controlled release. Polym. Bull. 2014, 71, 3163-3176. [CrossRef]

54. Ball, C.; Chou, S.F.; Jiang, Y.; Woodrow, K.A. Coaxially electrospun fiber-based microbicides facilitate broadly tunable release of maraviroc. Mater. Sci. Eng. C 2016, 63, 117-124. [CrossRef]

55. Han, S.O.; Son, W.K.; Youk, J.H.; Lee, T.S.; Park, W.H. Ultrafine porous fibers electrospun from cellulose triacetate. Mater. Lett. 2005, 59, 2998-3001. [CrossRef]

56. Wang, M.; Wang, L.; Huang, Y. Electrospun hydroxypropyl methyl cellulose phthalate (HPMCM/ Erythromycin fibers for targeted release in intestine. J. Appl. Polym. Sci. 2007, 106, 2177-2184. [CrossRef]

57. Frenot, A.; Henriksson, M.W.; Walkenstrom, P. Electrospinning of cellulose-based nanofibers. J. Appl. Polym. Sci. 2007, 103, 1473-1482. [CrossRef] 
58. Duan, B.; Huang, Y.; Lu, A.; Zhang, L.N. Recent advances in chitin based materials constructed via physical methods. Prog. Polym. Sci. 2018, 82, 1-33. [CrossRef]

59. Tripathi, K.; Singh, A. Chitin, chitosan and their pharmacological actives: A review. Int. J. Pharm. Sci. Res. 2018, 9, 2626-2635.

60. Mottu, F.; Laurent, A.; Rufenacht, D.A.; Doelker, E. Organic solvents for pharmaceutical parenterals and embolic liquids: A review of toxicity data. PDA J. Pharm. Sci. Technol. 2000, 54, 456-469.

61. Ahsan, S.M.; Thomas, M.; Reddy, K.K.; Sooraparaju, S.G.; Asthana, A.; Bhatnagar, I. Chitosan as biomaterial in drug delivery and tissue engineering. Int. J. Biol. Macromol. 2018, 110, 97-109. [CrossRef]

62. Kumar, M.; Muzzarelli, R.A.A.; Muzzarelli, C.; Sashiwa, H.; Domb, A.J. Chitosan chemistry and pharmaceutical perspectives. Chem. Rev. 2004, 104, 6017-6084. [CrossRef]

63. Portero, A.; Remunan-Lopez, C.; Criado, M.T.; Alonso, M.J. Reacetylated chitosan microspheres for controlled delivery of anti-microbial agents to the gastric mucosa. J. Microencapsul. 2002, 19, 797-809. [CrossRef]

64. De Campos, A.M.; Sanchez, A.; Alonso, M.J. Chitosan nanoparticles: A new vehicle for the improvement of the delivery of drugs to the ocular surface. Application to cyclosporin A. Int. J. Pharm. 2001, 224, 159-168. [CrossRef]

65. Prego, C.; Garcia, M.; Torres, D.; Alonso, M.J. Transmucosal macromolecular drug delivery. J. Control. Release 2005, 101, 151-162. [CrossRef]

66. Vila, A.; Sanchez, A.; Janes, K.; Behrens, I.; Kissel, T.; Jato, J.L.V.; Alonso, M.J. Low molecular weight chitosan nanoparticles as new carriers for nasal vaccine delivery in mice. Eur. J. Pharm. Biopharm. 2004, 57, 123-131. [CrossRef]

67. Chen, G.K.; Fang, D.W.; Wang, K.M.; Nie, J.; Ma, G.P. Core-Shell Structure PEO/CS Nanofibers Based on Electric Field Induced Phase Separation via Electrospinning and Its Application. J. Polym. Sci. Part A Polym. Chem. 2015, 53, 2298-2311. [CrossRef]

68. Zhou, Y.; Yang, D.; Chen, X.; Xu, Q.; Lu, F.; Nie, J. Electrospun water-soluble carboxyethyl chitosan/poly(vinyl alcohol) nanofibrous membrane as potential wound dressing for skin regeneration. Biomacromolecules 2008, 9, 349-354. [CrossRef]

69. da Silva, S.B.; Krolicka, M.; van den Broek, L.A.M.; Frissen, A.E.; Boeriu, C.G. Water-soluble chitosan derivatives and $\mathrm{pH}$-responsive hydrogels by selective C-6 oxidation mediated by TEMPO-laccase redox system. Carbohydr. Polym. 2018, 186, 299-309. [CrossRef]

70. Shields, K.J.; Beckman, M.J.; Bowlin, G.L.; Wayne, J.S. Mechanical properties and cellular proliferation of electrospun collagen type II. Tissue Eng. 2004, 10, 1510-1517. [CrossRef]

71. Kolacna, L.; Bakesova, J.; Varga, F.; Kostakova, E.; Planka, L.; Necas, A.; Lukas, D.; Amler, E.; Pelouch, V. Biochemical and biophysical aspects of collagen nanostructure in the extracellular matrix. Physiol. Res. 2007, 56, S51-S60. [PubMed]

72. Parodi, R.; Carusi, G.; Santarelli, G.; Nanni, F.; Pingitore, R.; Brunel, G. Guided tissue regeneration employing a collagen membrane in a human periodontal bone defect: A histologic evaluation. Int. J. Periodontics Restor. Dent. 1997, 17, 283-291.

73. Pal, P.; Dadhich, P.; Srivas, P.K.; Das, B.; Maulik, D.; Dhara, S. Bilayered nanofibrous 3D hierarchy as skin rudiment by emulsion electrospinning for burn wound management. Biomater. Sci. 2017, 5, 1786-1799. [CrossRef]

74. Zhang, M.; Li, Z.Q.; Jiang, P.; Lin, T.; Li, X.Q.; Sun, D.H. Characterization and cell response of electrospun Rana chensinensis skin collagen/poly(l-lactide) scaffolds with different fiber orientations. J. Appl. Polym. Sci. 2017, 134, 45109. [CrossRef]

75. Brown, J.H.; Das, P.; DiVito, M.D.; Ivancic, D.; Tan, L.P.; Wertheim, J.A. Nanofibrous PLGA electrospun scaffolds modified with type I collagen influence hepatocyte function and support viability in vitro. Acta Biomater. 2018, 73, 217-227. [CrossRef]

76. Luo, J.N.; Tong, Y.W. Self-Assembly of Collagen-Mimetic Peptide Amphiphiles into Biofunctional Nanofiber. ACS Nano 2011, 5, 7739-7747. [CrossRef]

77. Numata, K.; Kaplan, D.L. Silk-based delivery systems of bioactive molecules. Adv. Drug Deliv. Rev. 2010, 62, 1497-1508. [CrossRef]

78. Ang, S.L.; Shaharuddin, B.; Chuah, J.A.; Sudesh, K. Electrospun poly(3-hydroxybutyrate-co-3-hydroxyhexanoate)/ silk fibroin film is a promising scaffold for bone tissue engineering. Int. J. Biol. Macromol. 2020, 145, 173-188. [CrossRef] 
79. Barnes, C.P.; Pemble, C.W.; Brand, D.D.; Simpson, D.G.; Bowlin, G.L. Cross-linking electrospun type II collagen tissue engineering scaffolds with carbodiimide in ethanol. Tissue Eng. 2007, 13, 1593-1605. [CrossRef]

80. Passerini, N.; Craig, D.Q.M. An investigation into the effects of residual water on the glass transition temperature of polylactide microspheres using modulated temperature DSC. J. Control. Release 2001, 73, 111-115. [CrossRef]

81. Siegel, S.J.; Kahn, J.B.; Metzger, K.; Winey, K.I.; Werner, K.; Dan, N. Effect of drug type on the degradation rate of PLGA matrices. Eur. J. Pharm. Biopharm. 2006, 64, 287-293. [CrossRef] [PubMed]

82. Pinzon-Garcia, A.D.; Cassini-Vieira, P.; Ribeiro, C.C.; Jensen, C.E.D.; Barcelos, L.S.; Cortes, M.E.; Sinisterra, R.D. Efficient cutaneous wound healing using bixin-loaded PCL nanofibers in diabetic mice. J. Biomed. Mater. Res. Part B Appl. Biomater. 2017, 105, 1938-1949. [CrossRef] [PubMed]

83. Zarghami, A.; Irani, M.; Mostafazadeh, A.; Golpour, M.; Heidarinasab, A.; Haririan, I. Fabrication of PEO/Chitosan/PCL/Olive Oil Nanofibrous Scaffolds for Wound Dressing Applications. Fibers Polym. 2015, 16, 1201-1212. [CrossRef]

84. Xue, J.J.; He, M.; Liu, H.; Niu, Y.Z.; Crawford, A.; Coates, P.D.; Chen, D.F.; Shi, R.; Zhang, L.Q. Drug loaded homogeneous electrospun $\mathrm{PCL} /$ gelatin hybrid nanofiber structures for anti-infective tissue regeneration membranes. Biomaterials 2014, 35, 9395-9405. [CrossRef]

85. Ferrand, A.; Eap, S.; Richert, L.; Lemoine, S.; Kalaskar, D.; Demoustier-Champagne, S.; Atmani, H.; Mely, Y.; Fioretti, F.; Schlatter, G.; et al. Osteogenetic Properties of Electrospun Nanofibrous PCL Scaffolds Equipped With Chitosan-Based Nanoreservoirs of Growth Factors. Macromol. Biosci. 2014, 14, 45-55. [CrossRef]

86. Duda, S.; Dreyer, L.; Behrens, P.; Wienecke, S.; Chakradeo, T.; Glasmacher, B.; Haastert-Talini, K. Outer Electrospun Polycaprolactone Shell Induces Massive Foreign Body Reaction and Impairs Axonal Regeneration through 3D Multichannel Chitosan Nerve Guides. Biomed Res. Int. 2014, 2014, 1-16. [CrossRef]

87. Lee, J.H.; Lee, H.B.; Andrade, J.D. Blood compatibility of polyethylene oxide surfaces. Prog. Polym. Sci. 1995, 20, 1043-1079. [CrossRef]

88. Buddhiranon, S.; DeFine, L.A.; Alexander, T.S.; Kyu, T. Genistein-Modified Poly(ethylene oxide)/ Poly(D,L-lactic acid) Electrospun Mats with Improved Antioxidant and Anti-inflammatory Properties. Biomacromolecules 2013, 14, 1423-1433. [CrossRef]

89. Qu, F.N.; Lin, J.M.G.; Esterhai, J.L.; Fisher, M.B.; Mauck, R.L. Biomaterial-mediated delivery of degradative enzymes to improve meniscus integration and repair. Acta Biomater. 2013, 9, 6393-6402. [CrossRef]

90. Spasova, M.; Stoilova, O.; Manolova, N.; Rashkov, I.; Altankov, G. Preparation of PLIA/PEG nanofibers by electrospinning and potential applications. Bioact. Compat. Polym. 2007, 22, 62-76. [CrossRef]

91. Sadri, M.; Karimi-Nazari, E.; Hosseini, H.; Emamgholi, A. New Chitosan/Poly(ethylene oxide)/Thyme Nanofiber Prepared by Electrospinning Method for Antimicrobial Wound Dressing. J. Nanostruct. 2016, 6, 322-328.

92. Koosha, M.; Mirzadeh, H. Electrospinning, mechanical properties, and cell behavior study of chitosan/PVA nanofibers. J. Biomed. Mater. Res. Part A 2015, 103, 3081-3093. [CrossRef]

93. Liu, X.L.; Xu, Y.J.; Wu, Z.Q.; Chen, H. Poly(N-vinylpyrrolidone)-Modified Surfaces for Biomedical Applications. Macromol. Biosci. 2013, 13, 147-154. [CrossRef]

94. Ding, B.; Kimura, E.; Sato, T.; Fujita, S.; Shiratori, S. Fabrication of blend biodegradable nanofibrous nonwoven mats via multi-jet electrospinning. Polymer 2004, 45, 1895-1902. [CrossRef]

95. Um, I.C.; Fang, D.F.; Hsiao, B.S.; Okamoto, A.; Chu, B. Electro-spinning and electro-blowing of hyaluronic acid. Biomacromolecules 2004, 5, 1428-1436. [CrossRef]

96. Formhals, A. Process and Apparatus for Preparing Artificial Threads. U.S. Patent 1,975,504, 2 October 1934.

97. Taylor, G. Electrically driven jets. Proc. R. Soc. Lond. Ser. A Math. Phys. Sci. 1969, 313, 453.

98. Li, D.; Xia, Y.N. Electrospinning of nanofibers: Reinventing the wheel? Adv. Mater. 2004, 16, 1151-1170. [CrossRef]

99. Theron, S.A.; Yarin, A.L.; Zussman, E.; Kroll, E. Multiple jets in electrospinning: Experiment and modeling. Polymer 2005, 46, 2889-2899. [CrossRef]

100. Thoppey, N.M.; Bochinski, J.R.; Clarke, L.I.; Gorga, R.E. Unconfined fluid electrospun into high quality nanofibers from a plate edge. Polymer 2010, 51, 4928-4936. [CrossRef]

101. Wu, D.; Huang, X.; Lai, X.; Sun, D.; Lin, L. High Throughput Tip-Less Electrospinning via a Circular Cylindrical Electrode. J. Nanosci. Nanotechnol. 2010, 10, 4221-4226. [CrossRef] 
102. Niu, H.; Wang, X.; Lin, T. Needleless Electrospinning: Developments and Performances. Nanofibers Prod. Prop. Funct. Appl. 2011, 2011, 17-36.

103. Wei, L.; Sun, R.; Liu, C.; Xiong, J.; Qin, X. Mass production of nanofibers from needleless electrospinning by a novel annular spinneret. Mater. Des. 2019, 179, 107885. [CrossRef]

104. Jonsson, J.L. For Centrifugal Machines. U.S. Patent 581,423, 27 April 1897.

105. Buzgo, M.; Rampichova, M.; Vocetkova, K.; Sovkova, V.; Lukasova, V.; Doupnik, M.; Mickova, A.; Rustichelli, F.; Amler, E. Emulsion centrifugal spinning for production of 3D drug releasing nanofibres with core/shell structure. RSC Adv. 2017, 7, 1215-1228. [CrossRef]

106. She, F.; Tan, L.; Kong, L. A Multifunction Centrifugal Spinning Device; China Intellectual Property Office (C.I.P. Office), Ed.; C.I.P.: Beijing, China, 2015.

107. Medeiros, E.S.; Glenn, G.M.; Klamczynski, A.P.; Orts, W.J.; Mattoso, L.H.C. Solution Blow Spinning: A New Method to Produce Micro- and Nanofibers from Polymer Solutions. J. Appl. Polym. Sci. 2009, 113, 2322-2330. [CrossRef]

108. Kumar, A.; Sinha-Ray, S. A Review on Biopolymer-Based Fibers via Electrospinning and Solution Blowing and Their Applications. Fibers 2018, 6, 45.

109. Singh, R.; Ahmed, F.; Polley, P.; Giri, J. Fabrication and Characterization of Core-Shell Nanofibers Using a Next-Generation Airbrush for Biomedical Applications. ACS Appl. Mater. Interfaces 2018, 10, 41924-41934. [CrossRef]

110. Koga, T.; Watanabe, T.; Higashi, N. Fabrication of Nucleobase-Functionalized Supramolecular Nanofiber through Peptide Self-Assembly. J. Nanosci. Nanotechnol. 2009, 9, 584-590. [CrossRef]

111. Tanha, S.; Rafiee-Tehrani, M.; Abdollahi, M.; Vakilian, S.; Esmaili, Z.; Naraghi, Z.S.; Seyedjafari, E.; Javar, H.A. G-CSF loaded nanofiber/nanoparticle composite coated with collagen promotes wound healing in vivo. J. Biomed. Mater. Res. Part A 2017, 105, 2830-2842. [CrossRef]

112. Yergoz, F.; Hastar, N.; Cimenci, C.E.; Ozkan, A.D.; Tekinay, T.; Guler, M.O.; Tekinay, A.B. Heparin mimetic peptide nanofiber gel promotes regeneration of full thickness burn injury. Biomaterials 2017, 134, 117-127. [CrossRef]

113. Sacks, M.S.; Merryman, W.D.; Schmidt, D.E. On the biomechanics of heart valve function. J. Biomech. 2009, 42, 1804-1824. [CrossRef]

114. Zhang, C.; Wen, J.H.; Yan, J.; Kao, Y.B.; Ni, Z.Q.; Cui, X.J.; Wang, H.Y. In situ growth induction of the corneal stroma cells using uniaxially aligned composite fibrous scaffolds. RSC Adv. 2015, 5, 12123-12130. [CrossRef]

115. Kakade, M.V.; Givens, S.; Gardner, K.; Lee, K.H.; Chase, D.B.; Rabolt, J.F. Electric field induced orientation of polymer chains in macroscopically aligned electrospun polymer nanofibers. J. Am. Chem. Soc. 2007, 129, 2777-2782. [CrossRef] [PubMed]

116. Han, D.; Steckl, A.J. Triaxial Electrospun Nanofiber Membranes for Controlled Dual Release of Functional Molecules. ACS Appl. Mater. Interfaces 2013, 5, 8241-8245. [CrossRef]

117. Khatri, Z.; Wei, K.; Kim, B.S.; Kim, I.S. Effect of deacetylation on wicking behavior of co-electrospun cellulose acetate/polyvinyl alcohol nanofibers blend. Carbohydr. Polym. 2012, 87, 2183-2188. [CrossRef]

118. Yu, D.G.; Yu, J.H.; Chen, L.; Williams, G.R.; Wang, X. Modified coaxial electrospinning for the preparation of high-quality ketoprofen-loaded cellulose acetate nanofibers. Carbohydr. Polym. 2012, 90, 1016-1023. [CrossRef] [PubMed]

119. Castillo-Ortega, M.M.; Najera-Luna, A.; Rodriguez-Felix, D.E.; Encinas, J.C.; Rodriguez-Felix, F.; Romero, J.; Herrera-Franco, P.J. Preparation, characterization and release of amoxicillin from cellulose acetate and poly (vinyl pyrrolidone) coaxial electrospun fibrous membranes. Mater. Sci. Eng. C Mater. Biol. Appl. 2011, 31, 1772-1778. [CrossRef]

120. Zilberman, M. (Ed.) Active Implants and Scaffolds for Tissue Regeneration. In Active Implants and Scaffolds for Tissue Regeneration; Studies in Mechanobiology, Tissue Engineering and Biomaterials; Springer: Berlin, Germany, 2011; pp. 1-514.

121. Yang, Y.; Xia, T.; Zhi, W.; Wei, L.; Weng, J.; Zhang, C.; Li, X. Promotion of skin regeneration in diabetic rats by electrospun core-sheath fibers loaded with basic fibroblast growth factor. Biomaterials 2011, 32, 4243-4254. [CrossRef]

122. Qian, W.; Yu, D.G.; Li, Y.; Liao, Y.Z.; Wang, X.; Wang, L. Dual Drug Release Electrospun Core-Shell Nanofibers with Tunable Dose in the Second Phase. Int. J. Mol. Sci. 2014, 15, 774-786. [CrossRef] 
123. Huang, Z.M.; He, C.L.; Yang, A.Z.; Zhang, Y.Z.; Hang, X.J.; Yin, J.L.; Wu, Q.S. Encapsulating drugs in biodegradable ultrafine fibers through co-axial electrospinning. J. Biomed. Mater. Res. Part A 2006, 77, 169-179. [CrossRef]

124. Zhao, Y.; Cao, X.; Jiang, L. Bio-mimic multichannel microtubes by a facile method. J. Am. Chem. Soc. 2007, 129, 764-765. [CrossRef] [PubMed]

125. Chen, H.; Wang, N.; Di, J.; Zhao, Y.; Song, Y.; Jiang, L. Nanowire-in-Microtube Structured Core/Shell Fibers via Multifluidic Coaxial Electrospinning. Langmuir 2010, 26, 11291-11296. [CrossRef] [PubMed]

126. Sin, D.Y.; Koo, B.R.; Ahn, H.J. Hollow lithium manganese oxide nanotubes using MnO2-carbon nanofiber composites as cathode materials for hybrid capacitors. J. Alloys Compd. 2017, 696, 290-294. [CrossRef]

127. Yoo, H.S.; Kim, T.G.; Park, T.G. Surface-functionalized electrospun nanofibers for tissue engineering and drug delivery. Adv. Drug Deliv. Rev. 2009, 61, 1033-1042. [CrossRef] [PubMed]

128. Park, K.; Ju, Y.M.; Son, J.S.; Ahn, K.D.; Han, D.K. Surface modification of biodegradable electrospun nanofiber scaffolds and their interaction with fibroblasts. J. Biomater. Sci. Polym. Ed. 2007, 18, 369-382. [CrossRef]

129. Janjic, M.; Pappa, F.; Karagkiozaki, V.; Gitas, C.; Ktenidis, K.; Logothetidis, S. Surface modification of endovascular stents with rosuvastatin and heparin-loaded biodegradable nanofibers by electrospinning. Int. J. Nanomed. 2017, 12, 6343-6355. [CrossRef] [PubMed]

130. Hassiba, A.J.; El Zowalaty, M.E.; Nasrallah, G.K.; Webster, T.J.; Luyt, A.S.; Abdullah, A.M.; Elzatahry, A.A. Review of recent research on biomedical applications of electrospun polymer nanofibers for improved wound healing. Nanomedicine 2016, 11, 715-737. [CrossRef]

131. Bai, Y.; Yang, H.; Yang, W.W.; Li, Y.C.; Sun, C.Q. Gold nanoparticles-mesoporous silica composite used as an enzyme immobilization matrix for amperometric glucose biosensor construction. Sens. Actuators B Chem. 2007, 124, 179-186. [CrossRef]

132. Choi, J.S.; Leong, K.W.; Yoo, H.S. In vivo wound healing of diabetic ulcers using electrospun nanofibers immobilized with human epidermal growth factor (EGF). Biomaterials 2008, 29, 587-596. [CrossRef]

133. Ranjbar-Mohammadi, M.; Rabbani, S.; Bahrami, S.H.; Joghataei, M.T.; Moayer, F. Antibacterial performance and in vivo diabetic wound healing of curcumin loaded gum tragacanth/poly(epsilon-caprolactone) electrospun nanofibers. Mater. Sci. Eng. C Mater. Biol. Appl. 2016, 69, 1183-1191. [CrossRef]

134. Casper, C.L.; Yamaguchi, N.; Kiick, K.L.; Rabolt, J.F. Functionalizing electrospun fibers with biologically relevant macromolecules. Biomacromolecules 2005, 6, 1998-2007. [CrossRef]

135. Metwally, M.; Cheong, Y.; Li, T.C. A review of techniques for adhesion prevention after gynaecological surgery. Curr. Opin. Obstet. Gynecol. 2008, 20, 345-352. [CrossRef] [PubMed]

136. Chen, C.; Lv, G.; Pan, C.; Song, M.; Wu, C.H.; Guo, D.D.; Wang, X.M.; Chen, B.A.; Gu, Z.Z. Poly(lactic acid) (PLA) based nanocomposites-a novel way of drug-releasing. Biomed. Mater. 2007, 2, L1-L4. [CrossRef] [PubMed]

137. Rosa, R.M.; Silva, J.C.; Sanches, I.S.; Henriques, C. Simultaneous photo-induced cross-linking and silver nanoparticle formation in a PVP electrospun wound dressing. Mater. Lett. 2017, 207, 145-148. [CrossRef]

138. Rujitanaroj, P.O.; Pimpha, N.; Supaphol, P. Wound-dressing materials with antibacterial activity from electrospun gelatin fiber mats containing silver nanoparticles. Polymer 2008, 49, 4723-4732. [CrossRef]

139. Yang, Y.; Li, X.; Cheng, L.; He, S.; Zou, J.; Chen, F.; Zhang, Z. Core-sheath structured fibers with pDNA polyplex loadings for the optimal release profile and transfection efficiency as potential tissue engineering scaffolds. Acta Biomater. 2011, 7, 2533-2543. [CrossRef]

140. Langer, R. New methods of drug delivery. Science 1990, 249, 1527-1533. [CrossRef]

141. Kamaly, N.; Yameen, B.; Wu, J.; Farokhzad, O.C. Degradable Controlled-Release Polymers and Polymeric Nanoparticles: Mechanisms of Controlling Drug Release. Chem. Rev. 2016, 116, 2602-2663. [CrossRef]

142. Fredenberg, S.; Wahlgren, M.; Reslow, M.; Axelsson, A. The mechanisms of drug release in poly(lactic-coglycolic acid)-based drug delivery systems-A review. Int. J. Pharm. 2011, 415, 34-52. [CrossRef]

143. Webber, W.L.; Lago, F.; Thanos, C.; Mathiowitz, E. Characterization of soluble, salt-loaded, degradable PLGA films and their release of tetracycline. J. Biomed. Mater. Res. 1998, 41, 18-29. [CrossRef]

144. Fu, Y.; Kao, W.J. Drug release kinetics and transport mechanisms of non-degradable and degradable polymeric delivery systems. Expert Opin. Drug Deliv. 2010, 7, 429-444. [CrossRef]

145. Saindane, N.; Vavia, P. Osmotic pellet system comprising osmotic core and in-process amorphized drug in polymer-surfactant layer for controlled delivery of poorly water-soluble drug. J. Pharm. Sci. 2012, 101, 3169-3179. [CrossRef] 
146. Patel, H.; Patel, M.M. Formulation and evaluation of controlled porosity osmotic drug delivery system of metoprolol succinate. Int. J. Pharm. Sci. Res. 2012, 3, 1761-1767.

147. Uhrich, K.E.; Cannizzaro, S.M.; Langer, R.S.; Shakesheff, K.M. Polymeric systems for controlled drug release. Chem. Rev. 1999, 99, 3181-3198. [CrossRef] [PubMed]

148. Marin, E.; Briceno, M.I.; Caballero-George, C. Critical evaluation of biodegradable polymers used in nanodrugs. Int. J. Nanomed. 2013, 8, 3071-3091.

149. Makadia, H.K.; Siegel, S.J. Poly Lactic-co-Glycolic Acid (PLGA) as Biodegradable Controlled Drug Delivery Carrier. Polymers 2011, 3, 1377-1397. [CrossRef] [PubMed]

(C) 2020 by the authors. Licensee MDPI, Basel, Switzerland. This article is an open access article distributed under the terms and conditions of the Creative Commons Attribution (CC BY) license (http://creativecommons.org/licenses/by/4.0/). 